University of New England

DUNE: DigitalUNE

4-2017

\title{
Competency Development In Community-Based Occupational Therapy
}

Sunny R. Winstead

University of New England

Follow this and additional works at: https://dune.une.edu/theses

Part of the Adult and Continuing Education Commons, Educational Assessment, Evaluation, and Research Commons, Educational Leadership Commons, and the Occupational Therapy Commons

(C) 2017 Sunny Winstead

\section{Preferred Citation}

Winstead, Sunny R., "Competency Development In Community-Based Occupational Therapy" (2017). All Theses And Dissertations. 110.

https://dune.une.edu/theses/110

This Dissertation is brought to you for free and open access by the Theses and Dissertations at DUNE: DigitalUNE. It has been accepted for inclusion in All Theses And Dissertations by an authorized administrator of DUNE:

DigitalUNE. For more information, please contact bkenyon@une.edu. 


\author{
By \\ Sunny R. Winstead \\ BA (Binghamton University) 1993 \\ MS (Virginia Commonwealth University) 1996
}

\begin{abstract}
A DISSERTATION
Presented to the Affiliated Faculty

Of the College of Graduate and Professional Studies at the University of New England

In Partial Fulfillment of Requirements

For the Degree of Doctor of Education
\end{abstract}

Portland \& Biddeford, Maine

May, 2017 
Copyright 2017 by Sunny R. Winstead 
Sunny R. Winstead

May 2017

Educational Leadership

\title{
COMPETENCY DEVELOPMENT IN COMMUNITY-BASED OCCUPATIONAL THERAPY
}

\begin{abstract}
Objective: The aims of this study were: a) to discover which strategies community-based occupational therapists (OTs) find most effective for developing the competencies that have been identified as unique to community-based occupational therapy (OT) practice, b) to examine respondents' perceptions of the effectiveness of their academic training and of current professional development resources, and c) to explore respondents' suggestions for improving academic training and continuing education for OTs in community-based practice. Methods: Data collection was completed using an electronic survey that targeted members of the American Occupational Therapy Association who have experience in community-based OT. The survey was completed by 81 OTs with a wide range of practice experience. Results: Across six competency categories, most respondents reported self-directed learning to be the most effective strategy for developing the skills needed for community-based OT practice. Professional development strategies such as formal OT education, continuing education, workplace trainings, and mentorship were chosen less frequently than self-directed learning. Most respondents rated their formal OT education and existing professional development options as either average or effective, however they also had many suggestions for improvement. The most common suggestions included increasing community-based fieldwork, increasing the role of communitybased practitioners in the education process through guest lecturing and adjunct teaching, increasing mentorship options, and providing more education specific to the knowledge needed
\end{abstract}


to practice and advance in diverse community-based settings. Conclusion: The findings of this study suggest that experienced OTs in community-based practice use self-directed learning as a primary strategy for developing competencies. The findings also suggest there may be more OT academic programs and continuing education providers can do to prepare and support OTs in community-based practice.

Keywords: Occupational therapy, community-based, competency, continuing education, professional development 


\title{
University of New England \\ Doctor of Education \\ Educational Leadership
}

This dissertation was presented

by

\author{
Sunny R. Winstead
}

It was presented on

April 6, 2017

and approved by:

Carey Clark, Ph.D, Lead Advisor

University of New England

Peter Fifield, Ed.D, Secondary Advisor

University of New England

Vicki Smith, Ed.D, MBA, OTR/L,

Affiliate Committee Member, Keuka College 


\section{ACKNOWLEDGEMENTS}

Thank you to the University of New England's instructors and advisors for providing a challenging and rewarding academic experience. Thank you to my accomplished and inspiring classmates; our collaboration over the past three years has been invaluable. Thank you to my friends and colleagues at Keuka College for advice, resources, technical support, and muchneeded encouragement. And a sincere and loving thank you to my husband Michael, and my sons Jared, Peter, and Matthew. 


\section{TABLE OF CONTENTS}

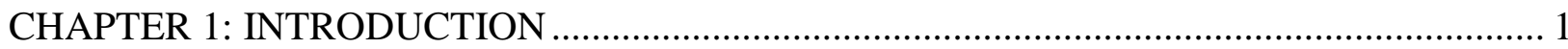

Statement of the Problem.................................................................................................. 2

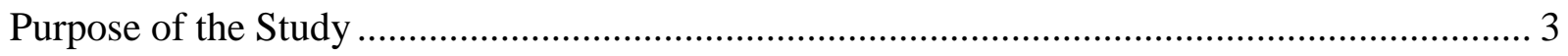

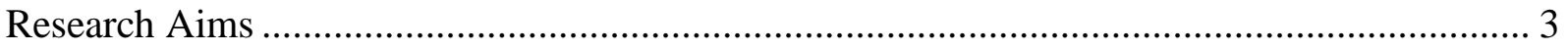

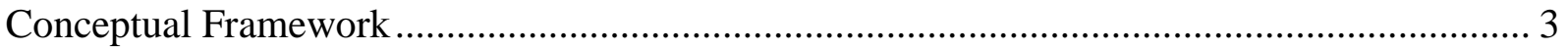

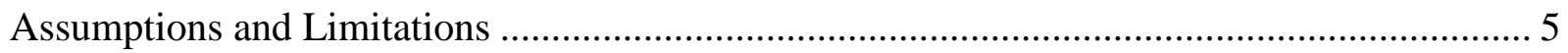

Rationale and Significance of the Study ...................................................................... 6

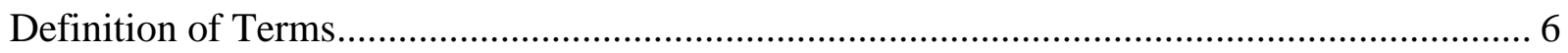

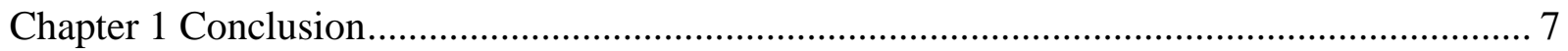

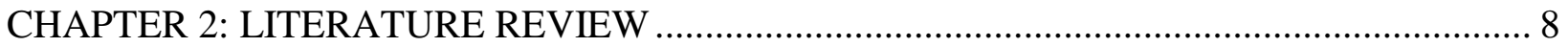

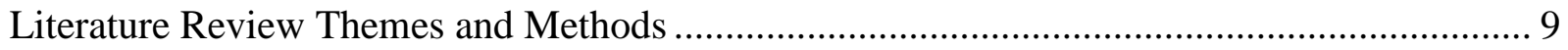

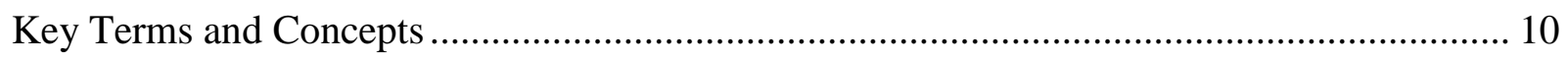

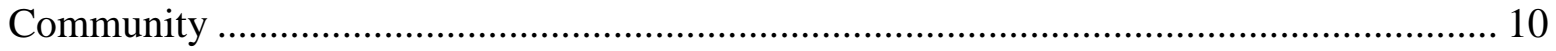

Community Practice and Community-Based Practice ............................................... 10

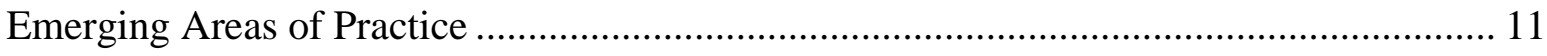

Competence and Competencies ........................................................................... 12

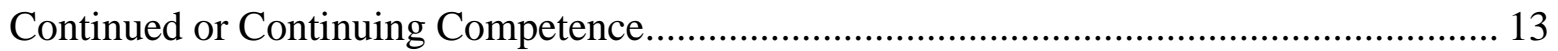

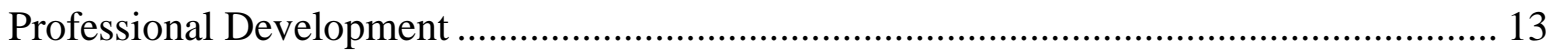

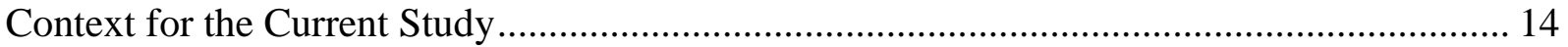


History of OT in Community-Based Practice

Recognized and Evolving Roles Within the OT Profession ........................................ 15

Theoretical Issues Affecting OT Roles .................................................................. 15

Trends in the US Health Care System ......................................................................... 17

Unique Competencies in Community-Based Practice.................................................... 18

Accreditation Council for Occupational Therapy Education (ACOTE) Standards ............. 18

General Competencies for Community-Based OT Practice ........................................ 19

Setting-Specific Competencies for Community-Based OT Practice ............................... 23

Personal Perspectives of Occupational Therapists in Community-Based Practice ................ 23

Professional Development for Community-Based OTs ................................................ 24

Theoretical and Practical Concepts Related to Professional Development ....................... 25

Professional Requirement Related to Professional Development ................................. 27

Research Findings Related to Professional Development ......................................... 28

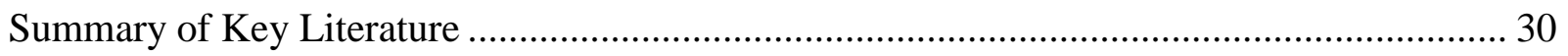

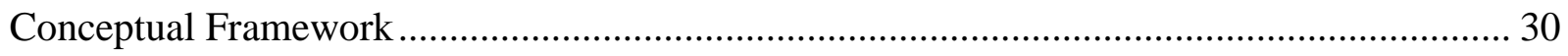

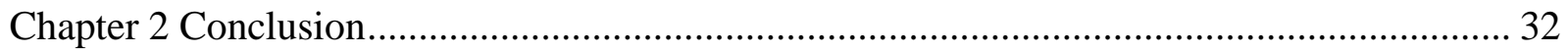

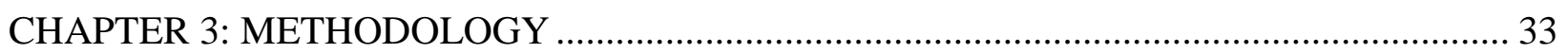

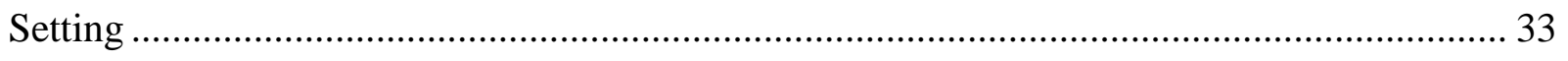

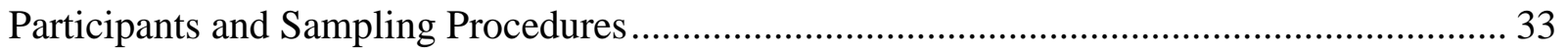

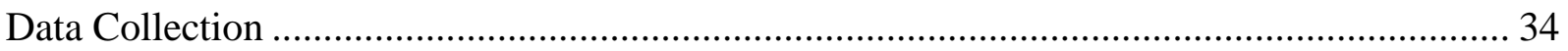




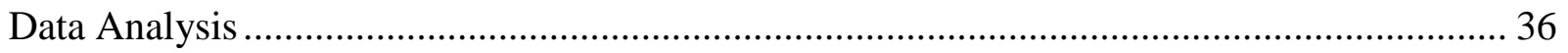

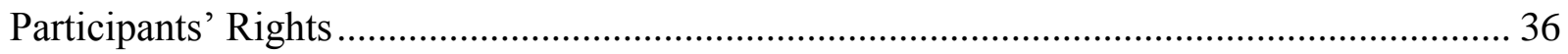

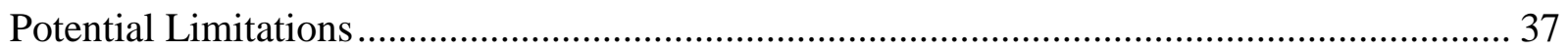

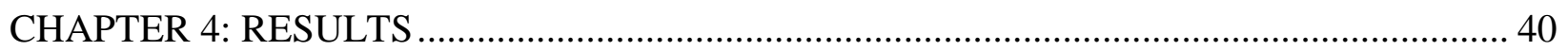

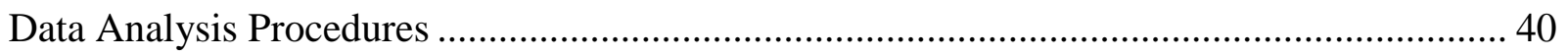

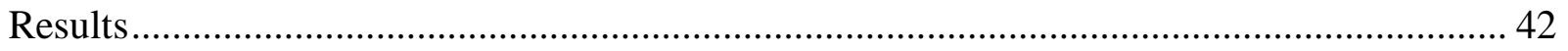

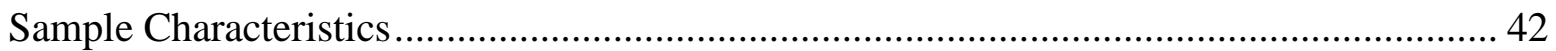

Competency Development ............................................................................................ 44

Effectiveness of Academic Training and Continuing Education Resources ........................ 50

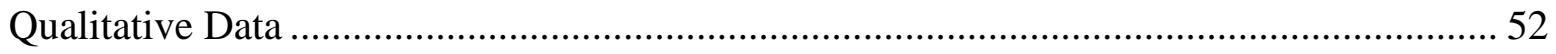

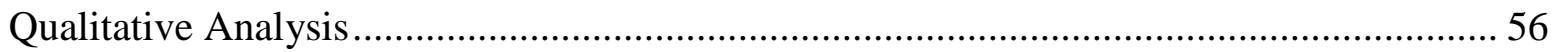

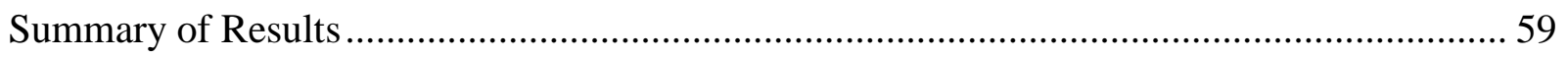

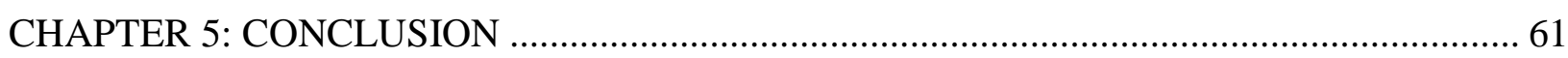

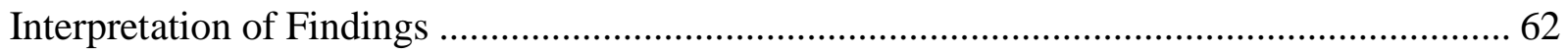

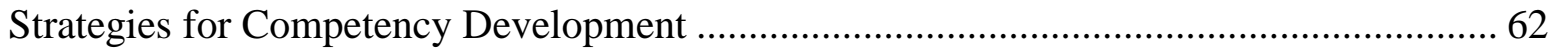

Effectiveness of Academic Training and Current Professional Development Options........ 68

Suggestions for Improving Academic Training and Continuing Education.......................... 71

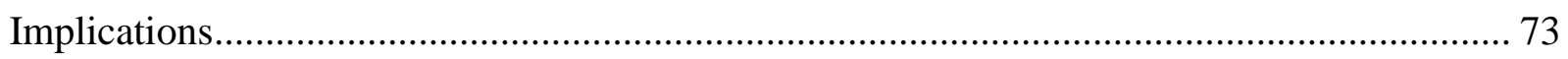

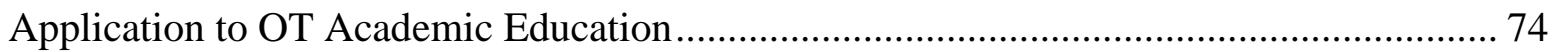

Application to Professional Development and Continuing Education ................................. 75 


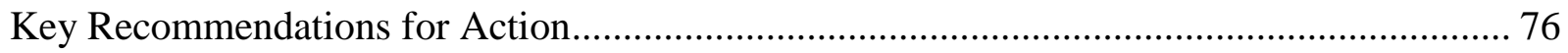

Recommendations for OT Programs …………………................................................ 76

Recommendations for Employers and Continuing Education (CE) Providers..................... 79

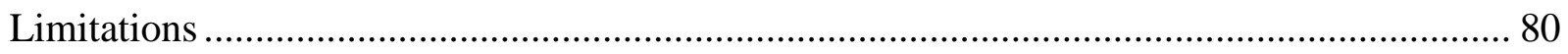

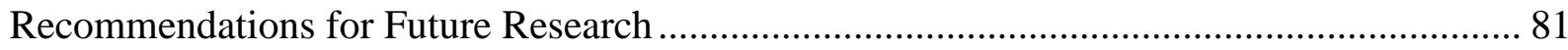

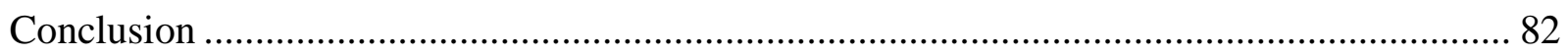

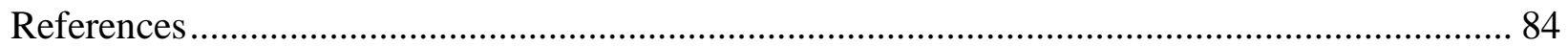

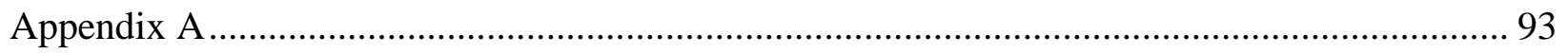

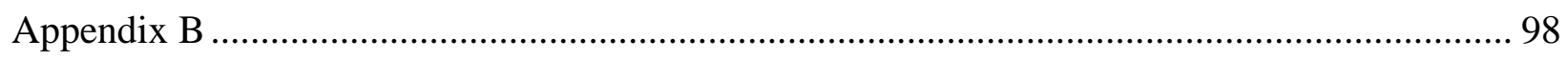

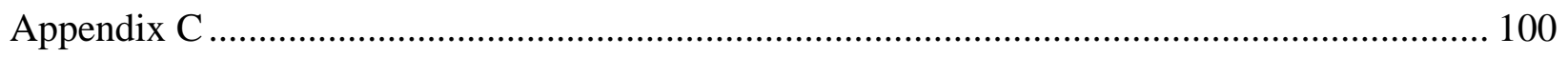

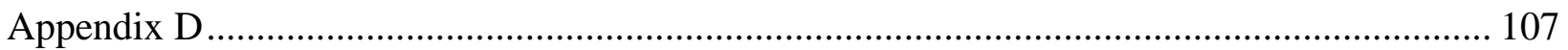

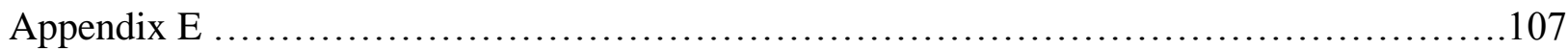




\section{LIST OF TABLES}

1. Selected ACOTE Standards Specific to Community-Based OT Practice .............................19

2. Study Respondents' Educational and Practice Backgrounds............................................43

3. Student Respondents' Areas of Community-Based Experience.........................................44

4. Suggestions for Improving OT Academic Preparation for Community-Based Practice.........53

5. Suggestions for Improving Continuing Education Resources ...........................................54 


\section{LIST OF FIGURES}

1. Most Effective Strategy for Developing Performance Skills .............................................45

2. Most Effective Strategy for Developing Specific Knowledge .........................................46

3. Most Effective Strategy for Developing Critical Reasoning Skills ...................................47

4. Most Effective Strategy for Developing Ethical Reasoning Skills.....................................48

5. Most Effective Strategy for Developing Interpersonal Communication Skills ....................49

6. Most Effective Strategy for Developing Personal Qualities and Characteristics ...................50

7. Respondents' Ratings of the Effectiveness of Academic Training and Professional

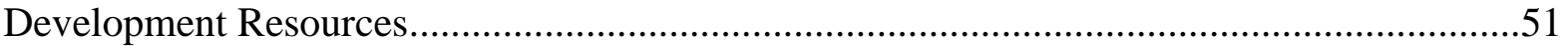




\section{CHAPTER 1}

\section{INTRODUCTION}

An occupational therapist (OT) enters an old farmhouse and her eyes slowly adjust to the dim light as she greets her patient, an older woman who lives alone and who recently experienced a minor stroke. The living room is crowded with heavy furniture, cardboard boxes, and piles of clothing; three cats lounge on the windowsill. There is a bed along one wall, dishes in the sink, and a jumble of pill bottles on the bedside table. The woman who lives here, Mrs. H., now lives in only a small part of the lower level; she has shut off most of the house to save money on heating costs and because she can no longer climb the stairs. This same woman was seen by a different OT in the hospital just last week, following her stroke. The hospital setting was quite different though: clean, bare rooms; structured routines; and a busy pace that limited casual conversation between patients and professionals. Mrs. H. is the same person in both settings, but the community-based OT needs specialized knowledge and skills in order to provide therapy that effectively meets Mrs. H.'s diverse needs within the context of her home environment.

Community-based practice includes a wide range of health-related services — acute and chronic medical care, prevention and health promotion, habilitation and rehabilitation—provided in community settings (Scaffa, 2014). This term can be contrasted with institution-based practice, which includes clinical services provided in institutional settings such as hospitals, nursing homes, and schools. Although the current literature is not extensive, it suggests that in addition to having competencies in common with their colleagues in institutional settings, community-based OTs also have competencies that are unique to working in the community. These unique community-based competencies cluster in six categories: (a) knowledge, (b) 
performance skills, (c) critical reasoning, (d) ethical reasoning, (e) interpersonal abilities, and (f) traits, qualities, and characteristics (Scaffa, 2014). In other words, the OT who works with Mrs. H. in her home will need slightly different skills as compared to her colleague in the rehabilitation hospital. These unique competencies will allow the community-based OT to address the complex and interwoven elements of Mrs. H.'s environment as they impact Mrs. H.'s functional, psychosocial, and medical needs.

The majority of OTs in the United States (US) work in institution-based settings (American Occupational Therapy Association [AOTA], 2015), and as a result, occupational therapy (OT) academic programs and continuing education resources have traditionally been geared toward supporting institution-based practice. However, with ongoing changes in the US health care system, OT practitioners may have opportunities to move into new community-based areas of practice (Brown, 2014; Fisher \& Friesema, 2013; Lamb \& Metzler, 2014), and to strengthen existing community-based roles such as home health care, early intervention, and mental health services. A better understanding of competency development may contribute to academic preparation and continuing education opportunities that more effectively prepare OTs to flourish in both current and future community-based roles.

\section{Statement of the Problem}

Although the research suggests that OTs in community-based practice have unique competencies as compared to their colleagues in institution-based practice (Holmes \& Scaffa, 2009a; Lysack, Stadnyk, Paterson, McLeod, \& Krefting, 1995; Ramsey, 2011), it is unclear how these competencies develop. Are OT educational programs successfully preparing students for community-based practice, or are there gaps? Are OTs in the community seeking specific continuing education or professional support? Are they able to find resources that meet their 
needs? Without a better understanding of competency development it is difficult to evaluate whether OT educational programs are effectively preparing students, or to determine whether existing professional development options are meeting the needs of OTs in diverse communitybased practice settings.

\section{Purpose of the Study}

This cross-sectional descriptive study explored the strategies used by community-based OT practitioners to develop the competencies that are unique to community-based OT practice, as defined by the literature. The results of the study may inform the development of more effective academic preparation and more tailored professional development resources.

\section{Research Aims}

This study aimed to discover which professional development strategies communitybased OTs find most effective to develop the competencies that have been identified as unique to community-based OT practice. Second, the study examined respondents' perceptions of the effectiveness of their academic training, and the perceived effectiveness of current professional development resources. Third, the study explored respondents' suggestions for improving academic training and continuing education for OTs in community-based practice.

\section{Conceptual Framework}

This study was guided by a conceptual framework that combined two evidence-based theoretical models: one describing community-based competencies and the second describing professional development. The study was also influenced by a clinical perspective that emphasized current community-based OT practice settings. Scaffa's 2014 framework of competencies for community-based and emerging OT practice defined the competency areas explored in this study: (a) knowledge, (b) performance skills, (c) critical reasoning, (d) ethical 
reasoning, (e) interpersonal abilities, and (f) traits, qualities, and characteristics. King's 2009 framework for the development of expertise defined the specific strategies for facilitating competence development explored in this study, as well as the strategy categories of personal experience, supports and resources, and workplace opportunities.

The researcher-developed questionnaire used in this study integrated the concepts of competency and professional development in order to better understand how OTs in communitybased practice become experts. The theoretical frameworks of Scaffa (2014) and King (2009) guided the formulation of questions that were consistent with the current literature and with current OT practice patterns. Respondents were asked to identify which professional development strategies (based on King's categories) they use and find effective in the development of particular community-based competencies (based on Scaffa's categories), as well as any strategies they use that are outside King's framework.

The conceptual framework of this study also incorporated a traditional definition of community-based practice. Although some OTs employed in emerging and innovative practice areas participated in the study, the study's emphasis was on OTs who worked in community settings in established OT roles. The settings identified in the AOTA Scope of Practice document provided a conceptual starting point: "home care, group homes, assisted living,... early intervention centers, day care centers, industry and business, hospice, sheltered workshops, transitional-living facilities, wellness and fitness centers, community mental health facilities” (AOTA, 2010, p. S75). Focusing on a traditional conceptualization of community-based OT practice was intended to maximize the applicability of study results by targeting a larger audience. It was also consistent with the researcher's personal experience of community-based practice. 


\section{Assumptions and Limitations}

This study may have been influenced by a number of assumptions held by the researcher based on a review of the literature and her own clinical experiences. Ideological assumptions identified prior to implementing the study included: (a) community based OT practice is distinct from institution-based OT practice, (b) OTs in community-based practice have unique competencies, (c) OTs in community-based practice engage in professional development, (d) OTs in community-based practice will understand the concepts of competence and professional development, (e) OTs in traditional areas of community-based practice (e.g. home health, early intervention, community mental health) will have insights relevant to competence development in community-based OT generally. Procedural assumptions identified prior to implementing the study included: (a) the researcher will obtain an adequate sample, (b) the sample will be representative of the target population, (c) the questionnaire developed by the researcher will be a valid means of assessing the research questions, and (d) respondents will provide honest and accurate information. These assumptions may have impacted the study's design and outcomes by shaping sampling decisions, formulation of survey questions, data analysis, and interpretation of results.

The study may have been limited by any of the preceding assumptions. For example, it is possible that OTs in community-based practice do not all possess unique competencies; if this is the case then some respondents may not have been able to offer meaningful insights. It is possible that respondents did not see a connection between their professional development activities and specific competencies identified in the literature. All licensed OT practitioners are required to engage in continuing education, but each practitioner applies and adapts that educational content to her/his own practice setting. Therefore, respondents may have had 
different interpretations of how continuing education applies to community-based practice competencies. Finally, design issues such as a relatively small sample size, low response rate, and the possibility of a non-representative sample may reduce the application and/or generalizability of study results.

\section{Rationale and Significance of the Study}

This study may contribute to a greater understanding of how OTs in community-based practice develop the unique competencies needed for practice in diverse settings. Competence not only assures effective, ethical services to clients in traditional areas of community-based practice, it may also enhance the ability of OTs to move into new practice areas. Since this study gathered data from OTs in practice, its primary purpose was to help clarify which professional development strategies were considered most effective for building specific community-based competencies. This data may be useful in the development of OT curricula and learning activities, as well as the design of professional development and continuing education resources for OTs in community-based practice. The intended audience for this study includes OT practitioners, OT educators, and individuals and organizations supporting OTs in communitybased practice, such as supervisors, mentors, and continuing education providers.

\section{Definition of Terms}

The following section provides definitions from the literature for several key terms used throughout this study. These terms are further described and contextualized in Chapter 2.

Community-based practice: "Includes a broad range of health-related services: prevention and health promotion, acute and chronic medical care, habilitation and rehabilitation, and direct and indirect service provision, all of which are provided in community settings" (Scaffa, 2014, p. 5). 
Competencies: "Explicit measures, indicators, or statements that define specific areas of knowledge, skills, and abilities related to essential functions and assigned duties within a role" (Braveman, 2016, p. 298).

Occupational therapy: "The therapeutic use of everyday life activities (occupations) with individuals or groups for the purpose of enhancing or enabling participation in roles, habits, and routines in home, school, workplace, community, and other settings" (AOTA, 2014, p. S1).

Professional development: "Approach that may include a program of continuing competence, but also includes a focus on one's career development in terms of achieving excellence or achieving independent practitioner or expert role status...” (Braveman, 2016, p. 299).

\section{Conclusion}

Community-based occupational therapy practice is complex. It includes the delivery of services to both individuals and groups within a variety of settings, and it often requires an understanding of systems and factors that are beyond entry-level training. This study explored how community-based competencies develop by examining which professional development strategies OTs found most effective, how they perceived the effectiveness of OT education programs and available professional development resources, and what suggestions they had for improving OT academic education and continuing education resources. The results may contribute to more effective academic preparation for OT students and more tailored professional development resources for OT practitioners. The following chapter will synthesize and evaluate the key literature that created the foundation for this study and will further describe the conceptual framework that guided the study design. 


\section{CHAPTER 2}

\section{LITERATURE REVIEW}

Occupational therapy (OT) practitioners help people across the lifespan participate in the things they want and need to do through the therapeutic use of everyday activities (American Occupational Therapy Association [AOTA], n.d., para. 2). Occupational therapists (OTs) have a holistic perspective, and they work with people in a wide variety of settings to achieve functional goals. Community-based practice includes interventions provided in community settings and designed to be responsive to the needs of individuals and families in homes, workplaces, and community agencies (Scaffa, 2014). This term is sometimes contrasted with institution-based practice, which refers to services provided in settings such as hospitals, nursing homes, and schools.

The purpose of this study was to describe how OTs develop specific competencies that are unique to community-based OT practice. Although the current literature is somewhat limited, there is evidence that OTs in community-based practice have unique knowledge, reasoning skills, interpersonal skills, and personal traits that help them succeed in complex and diverse settings. However, there is little evidence about how these competencies develop. With changes in health care and the potential for new opportunities in community-based services, it is important to know what competencies are unique to this area of practice, as well as how OTs develop these competencies. This knowledge may eventually contribute to the creation of curricular designs and professional development opportunities that more effectively prepare OTs for both traditional and new areas of community-based practice. 


\section{Literature Review Themes and Methods}

This integrative literature review presents, synthesizes, and assesses a broad range of literature related to (a) key terms and concepts; (b) the social, political, theoretical, and historical issues affecting community-based OT practice; (c) the skills and competencies unique to community-based practice; (d) the perceptions of OTs in community-based practice; and (e) professional development for community-based practice. Contextual content-key terms, theory, history, etc.- - is provided to help the reader understand the background of the study. Research literature describing community-based competencies is covered at length because it is the foundation upon which the current study is built. Although there are gaps in this literature, it provides sufficient evidence for identifying unique competency areas. This review also includes background on professional development generally, which is intended to place the study of OT competency development within the broader context of professional development. There is little research specific to professional development in community-based OT however, and this study attempted to address two identified gaps: how competency development occurs in OT (Braveman, 2016) and the relative effectiveness of various professional development strategies (King, 2009). This study's conceptual framework drew on evidence-based models that identify and categorize unique competencies for community-based OT practice, and strategies to foster the development of expertise in community-based practice generally.

Contextual material was obtained primarily from foundational sources that helped define key terms and concepts related to community-based OT service provision. Content describing competencies, competency development, and clinicians' perceptions came primarily from peerreviewed research studies. Preferred sources were those published between 2006 and 2016, but some earlier works were included, particularly those by influential scholars that helped to 
establish context for the research question. The primary search strategy was the use of online databases_-including Academic Search Premier, CINAHL, ERIC, Health Source, and PsychARTICLES — to locate peer-reviewed articles. Books were accessed both electronically (through keyword database searching) and through an institutional library. In addition to database searching, snowball techniques were employed, including back-checking references of influential articles, talking with colleagues, and serendipity searching.

\section{Key Terms and Concepts}

The following sections briefly define and discuss key terms used throughout the literature and in this study. Because the literature on community-based OT competencies is diverse-it comes from various countries, professional perspectives, and areas of practice - the use of the following key terms was not consistent. Terms were often found to overlap, or to be used differently based on authors' theoretical orientations and practice settings.

\section{Community}

The broadest term in the literature on this topic was community itself. Most attempts to define this term included a combination of elements, including physical location; individual people who share common interests, perspectives, and purpose; and identifiable social or cultural connections (Fazio, 2008; Scaffa, 2014). Scaffa (2014) described communities as groups of people or social units who come together for common purposes, and also as the spaces where people come together to live their lives. She noted that "no single definition appears to capture the richness and diversity of the term" (Scaffa, 2014, p. 5).

\section{Community Practice and Community-Based Practice}

Both terms refer to a broad range of health and social services, of which OT can be one example. Community practice refers to interventions that are provided within community settings 
and are designed to be responsive to the needs of individuals and families in homes, workplaces, and community agencies (Scaffa, 2014). Community practice is sometimes described within a social justice perspective, since these interventions are frequently intended to meet the unique needs of individuals and groups who have been under-served by traditional health and human services models (Meyers, 2010). The term community-based practice is usually used when the defining characteristic of the service is simply its location, and according to Fazio (2008), this use of locale as a central descriptor has been accepted across various disciplines. The AOTA Scope of Practice document provided the following examples of home and community settings: "home care, group homes, assisted living, schools, early intervention centers, day care centers, industry and business, hospice, sheltered workshops, transitional-living facilities, wellness and fitness centers, community mental health facilities" (AOTA, 2010a, p. S75). The term community-based practice (rather than community practice) was used throughout this study, since it reflects a more traditional, setting-based perspective that was consistent with current United States' (US) practice patterns and this study's conceptual framework. Community-based is sometimes contrasted with institution-based, but it should be noted that neither term is consistently or definitively defined in the literature.

\section{Emerging Areas of Practice}

Emerging areas of practice is a term used in several of the studies included in this review. The term can be found in the research literature and in practice across disciplines such as physical therapy, speech language pathology, and nursing. For example, the American SpeechLanguage-Hearing Association (ASHA) defined emerging areas of clinical practice as "new areas of practice for which clinicians are being asked to perform a new procedure, work with a new population, apply an existing treatment approach to a new population, or use a new service 
delivery model. The new area may or may not be in the current scope(s) of practice" (ASHA, 2008, sect. C). AOTA's website uses the term emerging niche to include potential new areas of practice ranging from telehealth, to obesity interventions for children, to veterans' mental health, to low vision services (Yamkovenko, n.d.), many of which are community-based. There is a lack of consensus around this term, however. In a 2009 pilot study by Holmes and Scaffa, the most common descriptor of emerging practice was "non-traditional," but this meant different things to each respondent (Holmes \& Scaffa, 2009b, p. 200). While some saw emerging areas of practice as important opportunities to broaden OTs' scope to include alternative models of care, others saw OTs' work in emerging areas as detrimental. No statistics were provided, but some respondents felt emerging practice might hurt traditional practice and might create confusion about OT’s identity and appropriate scope (Holmes \& Scaffa, 2009b).

\section{Competence and Competencies}

These related terms--found in the literature across many disciplines--are not consistently defined and are often used in different ways. In his text on OT leadership and management, Braveman (2016) defined competence as "the knowledge, critical thinking, motives, traits, characteristics, or skills to achieve a specific goal or perform job responsibilities" (p. 298). According to Parry (1998), a competency is "a cluster of related knowledge, attitudes and skills that affect a major part of one's job..." (p. 60). These definitions suggest the complexity of the terms. Competency is a broader term than skill (simply knowing how to do something) because it relates to job performance that requires the integration of multiple skills (Braveman, 2016). Braveman (2016) cited Patricia Benner's 1984 model of skill acquisition--clinicians move from novice to advanced beginner to competency to proficiency to expert—but noted that there is little in the literature to explain how competencies develop. Scaffa (2014) also used the concept of 
competencies, drawing on research and the AOTA Standards for Continuing Competence to identify six clusters of competencies needed for community-based and emerging OT practice. These competency clusters_-knowledge; performance skill; clinical reasoning; ethical reasoning; interpersonal abilities; and traits, qualities and characteristics (Scaffa, 2014)—provided the working definition of competency for this study.

\section{Continued or Continuing Competence}

Braveman (2016) defined continued or continuing competence as "the dynamic and multidimensional processes in which occupational therapy practitioners develop and maintain the knowledge, performance skills, interpersonal abilities, critical reasoning, and ethical reasoning skills necessary to perform current and future roles..." (p. 298-299). AOTA (2010b) stated that continuing competence is "a process involving the examination of current competence and the development of capacity for the future" (p. S103), which suggests it includes not just skill maintenance but also the ability to self-assess in order to identify growth and development needs.

\section{Professional Development}

Professional development can be defined as the process of obtaining the skills, experience, and qualifications that allow for career advancement (Professional development, n.d.). This term is sometimes used synonymously with continued or continuing competence, but according to AOTA (2010b), continuing competence is a component of professional development and lifelong learning. Braveman (2016) also stated that professional development includes continuing competence. Professional development may include a program of continuing competence (attending conferences, accessing online training resources, etc.), but it also focuses on career development in a broader sense, including such concepts as achieving excellence, and assuming new roles and responsibilities (Braveman, 2016). Professional development was the 
preferred term for this study, since it has a broader scope and therefore, aligns well with an exploratory study.

\section{Context for the Current Study}

This section provides an overview of the historical, clinical, and theoretical issues impacting community-based OT. It includes a review of background literature describing the development of community-based OT practice, current and future roles of practitioners working in the community, and the theoretical debate surrounding how community-based practice is conceptualized by scholars and OT practitioners.

\section{History of OT in Community-Based Practice}

Community-based OT practice dates back to the earliest days of the profession, notably in mental health practice (Meyers, 2010; Scaffa, 2014). After World War II however, there was a shift toward hospital-based services to meet the needs of injured veterans. OT joined other professions in adopting the biomedical model (Meyers, 2010; Scaffa, 2014), with its emphasis on physical function and the absence of disease as primary indicators of health. As a result of this shift, OT became associated with medical and rehabilitative services, primarily in institutional settings, and educational programs responded by adjusting their curriculum to the realities of practice (Scaffa, 2014). Since the 1970s some leaders of the profession have promoted a return to the more holistic, occupation-based roots of the profession, including the development of the skills needed to succeed in community-based practice (Fidler, 2000; Fidler, 2001; McColl, 1998). Wilma West was a particularly respected voice for change in the second half of the twentieth century, writing in 1968, "it matters most of all that we recognize the responsibility of the profession to change with changing demands for its services, to adapt via new approaches, to assume different roles, to develop the preparation for them..." (as cited in Gillette, 1998). As of 
$2014,15.8 \%$ of OTs reported practicing primarily in community-based settings, including $6.8 \%$ in home health, $4.6 \%$ in early intervention, $2.4 \%$ in mental health, and $2 \%$ in community (AOTA, 2015b, p. 4).

\section{Recognized and Evolving Roles Within the OT Profession}

Scaffa (2014) noted that many positions that could be filled by OTs in the community are not explicitly identified as OT jobs. Therefore, OTs who want to expand their roles must be trailblazers, confident in and able to articulate their unique skills and competencies. Baum (2006) recognized that OTs in community practice may not be direct service providers, and this is consistent with AOTA's inclusion of language in official documents that includes prevention and health promotion roles. For example, the third edition of the Occupational Therapy Practice Framework (AOTA, 2014) refers not only to services to clients (OTs' tradition individual-level focus) but also services to groups and populations, reflecting a shift toward an inclusion of population-level interventions within the profession's identified scope of practice.

The Accreditation Council for Occupational Therapy Education (ACOTE®) also validates OTs' role in community practice--including prevention and health promotion--stating that graduates of accredited programs will be able to provide occupation-centered services to individuals or populations "in home, school, workplace, community, and other settings" (ACOTE, 2011, p 1). Although primarily focused on individual client services, the AOTA Scope of Practice also states that services are provided "to persons, organizations, and populations" (AOTA, 2010a, p. S75).

\section{Theoretical Issues Affecting OT Roles}

Although some OT services provided in community settings are consistent with the biomedical model, many fit more closely with occupation-based, client-centered, systems-based 
models. A systems approach emphasizes the complex and dynamic interactions that occur between individuals, environments, and occupations (Fazio, 2008; Scaffa, 2014), and recognizes a broad range of factors as relevant to occupational performance (Scaffa, 2014). Scaffa (2014) pointed out that community-based services are more than just an extension of the medical model into community settings; they are part of a new paradigm that she called the community practice paradigm (p. 11). Kendall, Muenchberger and Catalano (2009) made a similar contention when they wrote that the trend toward community-based rehabilitation (CBR) requires a "true paradigm shift," not simply the transplantation of institutionally-based practices into community settings (p. 2171). CBR is a loosely defined international model originally developed by the World Health Organization (WHO) as a way to improve the quality of life for people with disabilities and their families through inclusion and participation (WHO, 2016).

A number of scholars have placed OT community practice within the context of social justice, noting that OT has the potential to promote social justice through prevention, health promotion, client empowerment, and service to the community as a whole (Fazio, 2008; Kendall et al., 2009; Meyers, 2010; Sakellariou \& Pollard, 2006). A social/occupational justice perspective is based on the premise that all individuals have a right to engage in valued occupations such as productive activities, leisure, and learning (Braveman \& Suarez-Balcazar, 2009). The concept of cultural competence is also central to a social justice approach to community practice, since both perspectives assume that clients and providers should share power and interact respectfully while working to meet individuals' needs (Meyers, 2010; Wray \& Mortenson, 2011).

In summary, although OT has professional roots in community-based intervention, many OTs today identify with the biomedical model which is typical of institution-based settings such 
as hospitals and nursing homes. While there is international support for CBR and communitybased services generally, most American OTs still practice in traditional settings and do not significantly integrate population-level interventions and/or social justice principles into everyday practice (Riegel \& Eglseder, 2009).

Documents from OT's professional association (AOTA) and national accrediting body (ACOTE) support traditional practice, wherein OTs serve individual clients, often in institutionbased settings. However, these same documents also support emerging roles for OTs with groups, communities, and populations. The conceptual framework for this study included a more traditional conception of community-based practice. This was not intended to diminish the potential value of new models of practice, but rather to recognize the realities of current OT practice in the US and to maximize the potential relevance of study results.

\section{Trends in the US Health Care System}

Although its future is now uncertain, some OT leaders advocated that the implementation of the Affordable Care Act of 2010 (ACA), might open up new opportunities for OT (Brown, 2014; Fisher \& Friesema, 2013; Lamb \& Metzler, 2014). For example, the ACA identified 10 essential health benefits (U.S. Department of Health and Human Services, n.d.), three of which could offer particular opportunities for community-based OT: rehabilitation and habilitation, mental health services, and preventive and wellness services. In addition, the ACA outlined a number of initiatives designed to improve quality of care while containing costs. Several of these initiatives, including the Independence at Home project, the Community-based Care Transitions program, and several primary care initiatives, have the potential to involve OTs in innovative, community-based models (Lamb \& Metzler, 2014). Other examples of new opportunities include the recent inclusion of OTs as suggested staff for certified community behavioral health clinics 
(AOTA, 2015a), New York's 2015 legislation allowing occupational therapists and physical therapists to provide telehealth services (New York State Assembly, n.d.), and the Jimmo vs. Sebelius settlement, which clarified that Medicare does not support an "improvement standard" as the sole basis for claims determination, thereby allowing additional clients to receive skilled therapy (Metzler, 2015). Health care is constantly changing and some of these changes may present opportunities for OTs who are interested in providing services—and perhaps new kinds of services - in community-based settings.

\section{Unique Competencies in Community-Based Practice}

Community-based OT can include a wide range of practice settings, services to both individuals and populations, and the need to understand systems and factors that are outside the entry-level training of many clinicians. Although community-based OT is recognized as a unique area of practice with unique challenges and opportunities, there is a somewhat limited body of literature pertaining to specific competencies. The following sections outline accreditation standards and existing research related to general OT competencies for community-based practice, as well as competencies specific to particular areas of community-based practice.

\section{Accreditation Council for Occupational Therapy Education (ACOTE) Standards}

ACOTE standards define learning objectives and other requirements that OT educational programs must meet to achieve and maintain accreditation. Section B of the current accreditation document includes standards that must be facilitated through coursework, and the majority of these standards are applicable across all areas of practice. There are several standards that specifically address community-based practice however, as summarized in Table 1 (ACOTE, 2011). Scaffa, Guillory Caraway, and Takehara (2014) noted that the new ACOTE standards adopted in 2011 include "a major emphasis on community and social systems" (p. 430). 
Table 1

Selected ACOTE® Standards Specific to Community-Based OT Practice

\begin{tabular}{ll} 
B. 2.5 & $\begin{array}{l}\text { Role of occupation in health promotion and } \\
\text { disease prevention for individuals, families, and } \\
\text { society } \\
\text { Use of home and community programming to } \\
\text { B. } 5.17\end{array}$ \\
$\begin{array}{ll}\text { support performance in the client's natural } \\
\text { environment } \\
\text { Health literacy, prevention, health maintenance, } \\
\text { health promotion and safety }\end{array}$ \\
B. 5.26 & $\begin{array}{l}\text { Use of the consultative process with groups, } \\
\text { programs, organization, and communities }\end{array}$ \\
B. 5.27 & $\begin{array}{l}\text { OT's role in care coordination, case management, } \\
\text { and transition services in traditional and emerging } \\
\text { practice } \\
\text { This group of standards includes understanding } \\
\text { the professional, social, cultural, political, and } \\
\text { ecological context for OT services in various } \\
\text { settings }\end{array}$ \\
\hline
\end{tabular}

Note: Adapted from Accreditation standards for a Masters-degree-level educational program for the occupational therapist, by Accreditation Council for Occupational Therapy Education, 2011, retrieved from http://www.aota.org/Education-

Careers/Accreditation/StandardsReview.aspx

\section{General Competencies for Community-Based OT Practice}

Research suggests that while community-based OTs have competencies in common with their colleagues in institution-based practice, they also have competencies that are unique to working in the community. Although relatively few studies have explored community-based OT competencies, there are a number of important findings. Lysack, Stadnyk, Paterson, McLeod, and Krefting (1995) published the earliest study located, based on a 1992 survey of 130 community-based Canadian OTs. Job skills identified by respondents as most important included 
communication, networking, client assessment, consultation, client education/treatment, charting, staff education/ inservices, and individual counseling (Lysack, et al., 1995). While the authors acknowledged sampling limitations, this study was one of the first to add specific data to the question of what makes community-based OT unique.

Several more recent studies have provided additional insights. Holmes and Scaffa (2009a) used the Delphi method to gather specific information about competencies and competence development from a group of 23 OT panelists. Through three rounds of responses, the panelists identified competencies in the following categories: knowledge; performance skills; critical reasoning; ethical reasoning; interpersonal abilities; and traits, qualities, and characteristics (Holmes \& Scaffa, 2009a). The specific skills identified in each category were analyzed quantitatively to suggest a hierarchy of importance. Within the knowledge and performance categories, most of the highest ranking items were associated with general OT practice (Holmes \& Scaffa, 2009a). These categories also contained items more specific to community-based practice however, including program development, community systems, public health, and consultation (Holmes \& Scaffa, 2009a). Similarly, many items within the interpersonal and traits categories could be associated with OTs and other professionals in various settings, and the authors noted the similarity to characteristics attributed to entrepreneurs and leaders (Holmes \& Scaffa, 2009a). Respondents also valued critical and ethical reasoning, and once again the results revealed several competencies that are specific to community-based practice, notably the ability to use principles of occupational and social justice (Holmes \& Scaffa, 2009a).

There was significant overlap between the personal traits identified by Holmes and Scaffa (2009a), and those found by Ramsey (2011), with both studies highlighting the importance 
flexibility, self-direction, and persistence. Ramsey (2011) conducted semi-structured interviews with 10 community-based OTs in order to explore the experiences and perceptions of this group. Five themes emerged from the data: (a) respondents liked the autonomy in their work, (b) respondents valued the opportunities for creativity that their work provided, (c) respondents found it satisfying to be able to motivate clients toward goals, (d) respondents felt specific personal traits facilitated their success in community-based practice, and (e) respondents felt the need for more professional support and recognition (Ramsey, 2011). Within the theme of personal traits, respondents identified the importance of independence, creativity, persistence, motivation, and flexibility (Ramsey, 2011).

Scaffa (2014) drew on the results of the 2009 Holmes and Scaffa study, in combination with AOTA's Standards for Continuing Competence, to create a framework of competencies and characteristics needed for community-based and emerging OT practice. This is the most current and integrated source to date on unique competencies, and was foundational to this study. That said, the sample from the Holmes and Scaffa (2009a) study did not fully meet this study's definition for community-based practice. Holmes and Scaffa used convenience sampling, and included 11 educators (out of 23 participants), while excluding OTs in home health, a practice area that clearly meets AOTA's definition for home and community (AOTA, 2010a). It seems likely that OT educators - although often involved in community-based learning projects and research — may have different perspectives on emerging or community-based practice than would OTs in direct practice.

According to Scaffa (2014), competencies needed for community-based or emerging practice cluster in six areas: (a) knowledge, (b) performance skills, (c) critical reasoning, (d) ethical reasoning, (e) interpersonal abilities, and (f) traits, qualities, and characteristics. Five of 
these categories align with AOTA's Standards for Continuing Competence (2010b). The remaining category — traits, qualities, and characteristics — is drawn directly from the Holmes and Scaffa (2009b) study and is also consistent with the theme of unique personal qualities identified in Ramsey's 2011 study. As such, the framework presented by Scaffa draws on the available research in this area, and is therefore the most comprehensive identification of unique competencies currently available, although it is by no means based on a large body of research.

Critical reasoning and ethical reasoning were identified by Scaffa (2014) as among the unique competencies for OTs in community-based practice. A number of studies have examined clinical reasoning in OT generally, but the research specific to community-based practice is limited. In a systematic review exploring clinical reasoning in community-based OT, Carrier, Levasseur, Bedard, and Derosiers (2010) found that community OTs' clinical reasoning is influenced by both internal and external factors. Practice context (an external factor) has a particularly strong impact on community OTs' clinical reasoning (Carrier et al., 2010), suggesting that because community-based practice occurs in many settings, it requires unique reasoning. Carrier's study also found that in comparison to OTs in other practice settings, community-based OTs used interactive reasoning most often, and they tended to use different dimensions of clinical reasoning simultaneously (Carrier et al., 2010).

Other authors have drawn similar conclusions, noting that using multiple forms of clinical reasoning simultaneously suits the complex decision-making required in early intervention (Hanft \& Anzalone, 2001) and home health (Mitchell \& Unsworth, 2004). While much remains unknown, the existing literature nonetheless suggests that community-based OTs may have a unique approach to clinical reasoning. If so, this approach may be related to the diverse contexts and situations encountered in community-based practice. One might imagine, 
for instance, that the reasoning involved with advocating for workplace accommodation for an individual with severe mental illness would be different from that required to address the educational and social needs of a Vietnamese-speaking family of a child with autism.

\section{Setting-Specific Competencies for Community-Based OT Practice}

Several studies have examined competencies in specific areas of community-based practice including home health, work-related services, and early intervention. In a 2013 systematic review, Adam, Peters, and Chipchase found that occupational and physical therapists in work-related practice need (a) workplace knowledge related to injury management and prevention, (b) communication skills, (c) work assessment and intervention skills, (d) clinical reasoning skills, and (e) professional behaviors (self-reflection, presence, and confidence). While many of the knowledge areas identified were context-specific, the more general competencies were consistent with findings from other researchers. One in particular was professional presence, which included ethical behavior and adaptability, along with communication and clinical reasoning skills (Adam et al., 2013). Many of these same competencies were identified by therapists and employers in a subsequent qualitative study of work-related practice (Adam, Strong, \& Chipchase, 2014). Bowman (2014) also noted that OTs in community-based ergonomic practice need to be skilled at assessing and responding to multiple environments, suggesting the need for the context-specific clinical reasoning identified by Carrier et al. (2011).

\section{Personal Perspectives of Occupational Therapists in Community-Based Practice}

Several studies have attempted to gain insight into the perspectives of OTs in community-based practice using exploratory or qualitative methodology. Findings have addressed perceived levels of preparation for community-based practice, perceived rewards and challenges experienced in community roles, and recommendations for preparing students. In 
general, OTs in these studies felt their educational programs prepared them effectively for traditional practice, but not for non-traditional/community-based practice (Ramsey, 2011; Wood, Fortune, \& McKinstry, 2013). Respondents in several studies noted the need for additional training in the areas of consultation, advocacy, use of community resources, health promotion and macro-level services to populations (Ramsey, 2011; Wood et al., 2013).

Workplace autonomy, opportunities for creativity, and the satisfaction of helping clients achieve goals have been identified as rewarding aspects of community-based practice (Ramsey, 2011). In addition, OTs surveyed by Holmes and Scaffa (2009b) identified promoting the profession, acting as change agents, serving under-served communities, and educating students as unique rewards experienced in community-based practice. Perceived challenges in community-based practice were more wide ranging; they included lack of reimbursement, insufficient funding and staffing, lack of understanding/value for OTs' role, feeling unsupported (Homes \& Scaffa, 2009b; Ramsey, 2011; Wood et al., 2013), lack of preparation based on entrylevel education (Adam et al., 2014), and a loss of specialization due to the team-based approach that characterizes community-based mental health practice (Fox, 2013). Several of these challenges are directly linked to the nature of community-based practice, since OTs often work in non-traditional roles without the profession support of other OTs and often within systems that lack traditional reimbursement structures.

\section{Professional Development for Community-Based OTs}

Because some community-based competencies appear to be unique, students may need specialized curricula to prepare for this area of practice, and clinicians working in the community may need unique professional development support. Although there have been some published descriptions of fieldwork education models, educational projects and assignments, curricula, and 
program models, there remains insufficient evidence to show which competencies should be taught, or to indicate which models and approaches are most effective in preparing OT students for community-based practice. There is even less in the literature that sheds light on the professional development processes and needs of community-based OT practitioners. The following sections provide an overview of key concepts related to professional development, AOTA continuing competency guidelines, and the existing research literature.

\section{Theoretical and Practical Concepts Related to Professional Development}

Professional development is a complicated topic that has been explored by international researchers, scholars, and practitioners across disciplines. Two concepts relevant to the study-just a sliver of the existing literature - are described in the following sections.

Lifelong learning. Lifelong learning includes a wide range of formal and informal learning opportunities that promote the development of new knowledge and skills, creativity, adaptability, career flexibility, and personal fulfillment (Alsop, 2013). Lifelong learning is broader than simply maintaining professional competence. It is a mindset that allows individuals to embrace learning throughout life, and to deal flexibly with change and transition (Alsop, 2013).

In a 2009 report, the Institute of Medicine (IOM) identified five broad areas of concern with the current continuing education system in US health care. One of these was that health professionals tend to focus on just meeting the minimal standards put forth by regulators, rather than truly reflecting on their own needs and using continuing education as an opportunity for development and lifelong learning (Institute of Medicine, 2009). The IOM's criticism of the current system of continuing education in healthcare was echoed by Webster-Wright in her extensive 2009 review of the literature across disciplines (with a focus on education). According 
to Webster-Wright (2009), empirical research supports professional learning that is lifelong, socially-situated, and connected to practice. While acknowledging some innovative and engaging models, Webster-Wright (2009) noted that many professional development programs are still simply episodic updates of information, delivered out of context and therefore failing to promote change or facilitate genuine professional growth. A 2010 survey of 902 United Kingdom (UK) physicians by Schostak et al. yielded similar results. Respondents identified two primary purposes for continuing education: keeping up to date, and confirming that they were following practices similar to other physicians (Schostak et al., 2010). Findings showed that respondents typically chose continuing education options that were within their comfort zones, rather than taking the opportunity to assess and strengthen personal development needs (Schostak et al., 2010).

Reflective practice. According to Schon (1983), there are two primary types of reflection used by professionals: reflection-in-action and reflection-on-action. Reflection-in-action occurs when practitioners are engaged in their professional work, and particularly when something unexpected happens (Schon, 1983). It is the process of "focus[ing] interactively on the outcomes of action, the action itself, and the intuitive knowing implicit in the action" while the action is taking place (Schon, 1983, p. 56). Reflection-on-action got very little space in Schon's influential book, but it is essentially described as a retrospective process of reflection that occurs after the action has been completed.

Moon (2004) and others have criticized Schon for a lack of precision in his use of terms, and for inconsistencies in his descriptions of key concepts. Regardless, the evidence of Schon's influence is apparent as one scans the literature. Self-reflection is considered an important component of professional development and lifelong learning by many scholars and clinicians 
(Murdoch-Eaton \& Whittle, 2012; Stovholt \& Starkey, 2010; Webster-Wright, 2009) and is one of the experiential strategies identified in King's 2009 framework for the development of therapist expertise. It is important to note however, that much of the literature on these topics comes from disciplines other than OT; there is essentially no literature exploring the postgraduation professional development process for OTs, particularly those in community-based practice.

\section{Professional Requirement Related to Professional Development}

OT practitioners are expected to engage in ongoing professional development in order to meet professional and ethical guidelines, and they are required to engage in professional development to meet legal requirements for licensure and certification.

AOTA official documents. Several researchers have recognized the need for greater support for OTs in community-based practice, advocating for enhanced mentorship, opportunities to share knowledge, research that validates this area of practice, and continuing education to enhance leadership and entrepreneurial skills (Carrier et al., 2010; Holmes \& Scaffa, 2009a; Holmes \& Scaffa, 2009b; Wood et al., 2013). The AOTA Standards of Continuing Competence identify the following expectations for all OTs: knowledge, critical reasoning, interpersonal skills, performance skills, and ethical practice (AOTA, 2010b). Because of their foundational nature, these standards were incorporated into the framework of competencies for emerging practice/community-based practice developed by Scaffa (2014). The AOTA Code of Ethics also states that OT practitioners must maintain competency through ongoing education in their fields of practice (AOTA, 2015c, p. 3).

Licensure and certification requirements. OT practice is regulated in all 50 states, with most states requiring licensure (AOTA, 2016). In addition to meeting state regulations, most OT 
practitioners also hold a certification from the National Board for Certification in Occupational Therapy (NBCOT). NBCOT certification requires 36 units of professional development activities within each three-year certification cycle, and this requirement is consistent with most states' licensure requirements (NBCOT, 2016).

\section{Research Findings Related to Professional Development}

While several studies discussed previously touched on the development of communitybased competencies (Holmes \& Scaffa, 2009a; Ramsey, 2011; Wood et al., 2013), there is very little literature to specifically guide practitioners in the development of the unique competencies needed in community-based practice. One exception is the work of King (2009), who presented a framework of strategies designed to build expertise for therapists in community-based practice. According to King (2009), expertise — exceptional adaptive performance in response to situations that contain uncertainty—is similar across disciplines, and includes personal qualities, skills and abilities, and knowledge. By analyzing the literature, King developed a framework consisting of 21 strategies for facilitating the development of competence and expertise. These strategies were then organized into three groups: personal experience, supports and resources, and workplace opportunities (King, 2009). King's framework provides a current, credible, and evidence-based way to examine the development of competencies in community-based OT. It addresses the need for continued competency development, since clinicians often require experience and training beyond their initial academic training to become effective in community-based intervention (Kendall et al., 2009).

Many of the 'personal experience' strategies identified in King's framework are based on experiential learning. Specific self-directed strategies included deliberately seeking opportunities to improve skills, seeking feedback, and reflecting/self-assessing to improve future performance 
(King, 2009). Strategies in the 'supports and resources' category emphasized instructional learning methods that help clinicians make sense of their experiences (King, 2009). Specifics included the use of progress assessment tools, frameworks to guide thinking and problem solving, and the use of coaching and mentoring (King, 2009). The third category, 'workplace opportunities,' included the contextual factors and resources that can facilitate the development of expertise (King, 2009). These included opportunities to work with complex caseloads; interdisciplinary teams; formal trainings; scenario-based group instruction; mentorship programs; opportunities for feedback, interaction, and reflection; and apprenticeship models (King, 2009). This links to Holmes and Scaffa's (2009a) finding that OTs in community-based practice would like more opportunities for continuing education relevant to innovative practice and more opportunities for mentorship of both students and clinicians.

King's (2009) framework provides a credible compilation and analysis of the literature related to the development of expertise in community-based clinicians (though not specific to OT). In addition to the three over-arching categories and numerous specific strategies, King (2009) also identified several compelling implications for practice. First, she noted that in addition to technical skills and knowledge, clinicians need to acquire various soft skillscommunication, interpersonal, self-reflection etc.- - which are not often explicitly taught (King, 2009). Second, feedback is extremely important in the process of self-reflection and eventual development of expertise, but clinicians in community-based practice often have fewer opportunities to receive feedback from knowledgeable colleagues (King, 2009). As noted by other authors, community-based OTs often value their independence, but the lack of a built-in peer group can leave some coping with a sense of professional isolation (Holmes \& Scaffa, 2009b; Mitchell \& Unsworth, 2004; Ramsey, 2011). Finally, King (2009) emphasized the 
important role that the workplace plays in the development of expertise. While there is often an emphasis on the steps individual clinicians must take in the professional development process, that process is most effective when it is supported by workplace culture and resources (King, 2009).

\section{Summary of Key Literature}

Literature specific to community-based competencies and the processes by which OTs develop these competencies remains limited. Many scholars have called for additional research to better understand the complex issues surrounding community-based practice and emerging areas of practice (Adam et al., 2013; Carrier et al., 2010; Holmes \& Scaffa, 2009a; Holmes \& Scaffa, 2009b; Ramsey, 2011; Wood et al., 2013). The literature that does exist supports the preliminary conclusion that there are competencies and skills unique to those OTs who practice in the community (as compared to their peers in institutional settings). These competencies include unique knowledge, patterns of communication, personal traits, and clinical reasoning.

Because some community-based competencies are unique, it can be assumed that some tailored preparation (for students) and professional development/continuing education (for clinicians) is appropriate. Recommendations have been made for specific student preparation (ACOTE, 2011; Hanft \& Anzalone, 2001; Holmes \& Scaffa, 2009a) and for ongoing professional development opportunities for clinicians (King, 2009; Holmes \& Scaffa, 2009a;

Kendall, et al., 2009). The existing research provides a foundation, but much more is needed to understand the current state of competency development in community-based OT practice.

\section{Conceptual Framework}

The purpose of this study was to explore the competency development of occupational therapists (OTs) in community-based practice, using survey methodology to examine how OTs 
develop the specialized knowledge, communication skills, clinical reasoning, and personal qualities that have been identified in the literature as unique to community-based OT practice. This study was guided by a conceptual framework that combined two evidence-based theoretical models: one describing community-based competencies and the second describing professional development. The study was also influenced by a clinical perspective that emphasized current community-based OT practice settings.

Scaffa's 2014 framework of competencies for community-based and emerging OT practice was used to define the competency areas explored in this study: (a) knowledge, (b) performance skills, (c) critical reasoning, (d) ethical reasoning, (e) interpersonal abilities, and (f) traits, qualities, and characteristics. King's 2009 framework for competence development was used to determine which mechanisms for professional development were explored. King's framework was based on a review of literature from multiple disciplines; as described, it identified strategies for facilitating the development of competence and expertise in communitybased practitioners and organized these strategies into three categories: personal experience, supports and resources, and workplace opportunities (King, 2009).

The questionnaire used in this study integrated the concepts of competency and professional development in order to better understand how OTs in community-based practice become experts. It was clearly not feasible to ask respondents about every possible competency or strategy. Therefore, the theoretical frameworks of Scaffa and King guided the formulation of questions that were specific enough to be meaningful, and consistent with the literature and current OT practice. Respondents were asked to identify which strategies (from among King's categories) they found most useful in the development of particular competencies (from among Scaffa's categories), as well as any strategies they used that are outside King's framework. 
The conceptual framework for this study incorporated a traditional definition of community-based practice. The settings identified in the American Occupational Therapy Association (AOTA) Scope of Practice formed a conceptual starting point: "home care, group homes, assisted living... early intervention centers, day care centers, industry and business, hospice, sheltered workshops, transitional-living facilities, wellness and fitness centers, community mental health facilities" (AOTA, 2010, p. S75). This emphasis reflects current practice patterns, since about $15.8 \%$ of OTs practice in more traditional community-based areas, while only a small fraction of that number practice in emerging areas of practice (AOTA, 2015b). By focusing on traditional community-based practice, the researched hoped to maximize the study's relevance to a larger number of clinicians, students, and educators.

\section{Chapter 2 Conclusion}

The majority of OTs work in institution-based settings such as hospitals, nursing homes, and schools (AOTA, 2015b). As a result, academic programs and continuing education resources have traditionally been geared in those directions. Only about $15.8 \%$ of OTs work in communitybased settings (AOTA, 2015b. p. 4), with a small fraction of that number in settings that might be considered emerging areas of practice. There seem to be trends supporting new opportunities for community-based and innovative practice, but it is unclear if and when these opportunities will emerge, or what form they may take. Community-based practice is complex. Research suggests that it requires unique knowledge, communication skills, personal attributes, and clinical reasoning skills, but research has not yet clarified how OTs in community-based practice develop these competencies. This study's findings may help to address that gap in the literature; future scholarship on this topic may contribute to improved academic curricula design and the development of effective professional development opportunities for clinicians in practice. 


\section{CHAPTER 3}

\section{METHODOLOGY}

The purpose of this study was to explore the strategies used by community-based occupational therapy (OT) practitioners to develop the specific competencies that are unique to community-based OT practice. This study used survey methodology guided by a conceptual framework that combined theoretical models describing community-based competencies and professional development, in the context of a clinical perspective that emphasized current community-based OT practice settings. The results of the study may eventually inform the development of more relevant professional development resources for occupational therapists (OTs) in community-based practice. The results may be of interest to OT clinicians, OT educators, and those who supervise, train, and support OTs in community-based practice.

\section{Setting}

This study employed national survey methodology using mailed cover letters that invited respondents to complete an online survey using QuestionPro software. Data were therefore generated in various locations, depending on where questionnaires were completed. Data compilation and analysis was managed through QuestionPro, and the researcher accessed responses through her institution-based QuestionPro account.

\section{Participants and Sampling Procedures}

The target population for this study was a group of 500 randomly-selected OTs who were subscribers to the American Occupational Therapy Association (AOTA) Home and Community Health Special Interest Section (SIS), Work and Industry SIS, and Mental Health SIS. AOTA maintains eleven special interest sections created to help OT practitioners access information about clinical practice, share resources, and network. The three SIS chosen were deemed most 
consistent with the study's definition of community-based practice. The target population was chosen because it is similar to the broader study population-OTs with community-based practice experience - and because it could be accessed. Late in the data collection process the survey link was also posted to the listservs of the three SIS.

Study participants (the sample) were those individuals who completed an electronic questionnaire. The researcher purchased a one-use list of 300 members of the Home and Community Health SIS, 100 members of the Work and Industry SIS, and 100 members of the Mental Health SIS. The rental request process allows researchers to select a SIS, as well as specific work areas within that SIS. Therefore, the target population was the 500 AOTA members who were primary subscribers to the above three SISs, and who also selected their work areas as one of the following: early intervention, home health, mental health setting, work/industry/ergonomics, or community-based (See Appendix A). This list was generated by AOTA and provided to the researcher electronically in the form of an Excel file. Generation of the list is the responsibility of AOTA and the researcher had no involvement with this process.

Once the list was received, the researcher mailed survey invitations to the 500 individuals. This was a one-time mailing as required by the terms of the list rental. The researcher certainly considered using electronic recruitment procedures. However AOTA does not maintain a database of members' e-mails; contact information is limited to mailing addresses. Online forums and other options were also explored, but ultimately traditional mailing was deemed the most feasible option for recruiting a sample of necessary size and composition.

\section{Data Collection}

Each member of the target population presumably received a letter inviting her/him to participate in the study (See Appendix B). This cover letter included a link to the online 
QuestionPro questionnaire, as well as a QR code that could be scanned with a smart phone. Either option linked the respondent directly to the QuestionPro website and the study questionnaire. Data were obtained from respondents who complete the questionnaire. The questionnaire was designed by the researcher based on the review of the literature and the study's conceptual framework. See Appendix C. The questionnaire was pilot tested with a small group of community-based practitioners who provided feedback on the clarity and content of the questions, the ease of understanding scales within the instrument, and the time and effort required to complete the survey process (including reading the cover letter and accessing the online survey). An expert in electronic survey design also reviewed the questionnaire and provide technical feedback.

The questionnaire consisted of three sections: demographics and background information, closed-ended questions, and one open-ended question. Questionnaires were anonymous. Demographics and background included professional title, education level, years in practice, years in community-based practice, area(s) of community-based practice, and confirmation that respondents met the study's inclusion criteria. In order for their data to be included in the study, respondents must have been OTs, and must have practiced an average of 15 hours/week or more in a community-based setting within the past three years. The pilot group included one individual who is not in current practice, but who met the criteria for inclusion by having practiced within the past three years. This was intended to clarify whether a practitioner with recent communitybased experience (e.g. a faculty member or a retired OT) could provide valid information even if she was not currently working in community-based practice. The feedback and responses of this tester indicated she understood the questions and concepts and could provide valid responses. 
Closed-ended questions were used to examine the study's first question: what strategies do community-based OTs find most effective for developing the competencies identified in the literature as unique to community-based practice? A series of six questions asked respondents to choose the strategy that they find most effective in developing each of the six competencies identified by Scaffa (2014). The response options corresponded to the categories of professional development identified by King (2009). In addition, there was an option for respondents to write in a strategy of their own choosing. Two additional closed-ended questions asked respondents to rate the effectiveness of their OT academic program in preparing them for community-based practice, and to rate the effectiveness of current professional development resources for community-based OTs. The questionnaire concluded with an open-ended question that asked respondents for their suggestions for improving academic preparation and continuing education options.

\section{Data Analysis}

Survey data were managed and analyzed using QuestionPro software. Because of the exploratory nature of the study, it was appropriate that descriptive statistics be the primary form of quantitative data analysis (Portney \& Watkins, 2015). Measures of frequency distribution were used to summarize respondents' responses to closed-ended questions, and these data were presented in bar graph form for ease of reading. Responses to the open-ended question were described and summarized in narrative form in the final report, based on the qualitative analysis procedures described in Chapter 4.

\section{Participants' Rights}

This study was conducted with the approval of the Institutional Review Board (IRB) at the University of New England (UNE), as well as the IRB at the college where the researcher is 
employed. See Appendix D. The IRBs at both institutions required a thorough application process consistent with federal law and accepted practice to protect the rights and welfare of individuals participating in human subjects research (UNE, 2010).

Participation in this study was voluntary and carried no identified risks or potential harm. Return of the questionnaire implied consent to have one's data included in the study (Portney \& Watkins, 2015), and respondents were given an option to receive a copy of the final abstract electronically if they chose to provide an e-mail address. Questionnaires were anonymous and demographic and background information did not include sensitive items. In order to ensure confidentiality, quantitative survey data were analyzed and presented in aggregate. Qualitative responses were also analyzed as a group and presented by theme. Individual qualitative responses (such as direct quotes) included in this manuscript do not include identifying information. All study materials have been secured and maintained by the researcher, and will be kept for a period of three years after the study is complete, in accordance with institutional requirements. Any data or analyses stored in QuestionPro are password-protected and accessible only to the researcher.

\section{Potential Limitations}

Dillman, Smythe, and Melani Christian (2014) detailed the increased use of mixed methods approaches for both contacting subjects and collecting data. This study used mixed methods to address the challenge of having only mailing addresses for the target population. A mailed invitation to participate was used in conjunction with an electronic survey. All-electronic survey methods were the researcher's preferred option, but AOTA only provides mailing addresses. After consulting with advisors, colleagues, and two content experts, it was decided that access to a large and specific target population was an advantage that outweighed the 
possible disadvantage associated with a mixed method approach. Multi-modal data collection was considered (i.e. providing a paper questionnaire as well as an electronic questionnaire) but single-mode data collection (i.e. electronic questionnaire only) was chosen to simplify and strengthen data management and analysis.

Dillman et al. (2014) identified four types of error common to surveys: coverage error, sampling error, non-response error, and measurement error. Each of these problems was identified in advance as a potential limitation for this study. Coverage error occurs when the list from which the sample is drawn does not represent the population (Dillman et al., 2014). In this case, the members of the Home and Community Health SIS, Work and Industry SIS, and Mental Health SIS are not necessarily representative of all US OTs in community-based practice. Members of these SIS are OTs who are also members of AOTA, and only about $28 \%$ of practicing OTs are members of the national association (C. Alterio, personal communication, September 28, 2016).

Sampling error is always a possibility whenever a sample is drawn from a target population, and in the case of this study it is possible that the sample might not have been representative of the entire membership of the three SIS. Non-response error was also identified as a potential limitation, since low response rate can (and did) limit sample size. Dillman et al. (2014) identified a number of factors affecting response rate. For example, individuals receiving a survey may resent the intrusion into their private time, may question the study's legitimacy, may be concerned about the time required to complete the survey, or just may not be interested in the study topic (Dillman et al., 2014). Some factors impacting response rate are inherent to survey design; others may be moderated by a well-designed method that minimizes the perception of cost and increases the perception of benefit (Dillman et al., 2014). 
Finally, measurement error occurs when the data obtained are not accurate. This can be due to lack of concept validity, questions that "lead" the respondent, unclear questions, question order or visual layout that influence responses, or question structure that encourages particular responses (Dillman et al., 2014). Any of these measurement concerns could limit this study, particularly because the instrument used was researcher-developed and did not have established reliability and validity. Pilot testing, advisor review, and consultation with an expert in electronic survey design reduced measurement concerns to some extent, but measurement still remains a potential source of error. In addition to the four types of error discussed already, this study may have been limited by the inexperience of the researcher, time limitations, and financial constraints. 


\section{CHAPTER 4}

\section{RESULTS}

The purpose of this study was to explore the strategies used by community-based occupational therapy (OT) practitioners to develop the specific competencies that are unique to community-based OT practice. Data were gathered through a national electronic survey that targeted occupational therapists (OTs) with current or recent experience in community-based practice. The following sections outline the study's data analysis procedures and results. Results are divided into three categories that correspond to questions or question groupings from the survey instrument (see Appendix C). Results related to competency development and respondents' perceptions of the effectiveness of academic training and professional development resources were drawn from the survey's closed-ended questions. Results related to recommendations for improving academic training and continuing education were drawn from the open-ended question that concluded the survey.

\section{Data Analysis Procedures}

The survey instrument designed for this study was created using the university version of QuestionPro software. All respondents completed the survey electronically, which allowed data to be gathered, organized, and analyzed using analytic features within the QuestionPro software. Because of the exploratory nature of the study, it was appropriate that descriptive statistics be the primary form of quantitative data analysis (Portney \& Watkins, 2015). Sample characteristics (from survey questions 1-8) and results related to competency development (from survey questions 9-14) were analyzed and reported using frequencies and percentages. Results related to the effectiveness of academic training and professional development options (from survey questions 15-16) were analyzed and reported using frequencies, percentages, means (M), and standard deviations (SD). All 81 surveys had usable responses to questions 1-16. 
Creswell's (2013) "data analysis spiral” (p. 182) was used to guide the qualitative analysis of the open-ended data. These data were derived from survey question 17 . The analysis process began with an organization of the data (Creswell, 2013). The qualitative comments related to respondents' suggestions for improving academic training and continuing education were tabulated by the QuestionPro software and then downloaded as an Excel spreadsheet. The researcher then began to get a sense of the data by reading through all of the comments several times, while jotting brief notes (Creswell, 2013). The next stage involved describing the data by developing codes (Creswell, 2013). The first level of coding employed an "open coding" or descriptive technique (Creswell, 2013, p. 86) using colored highlighters to tag elements within each written comment. Open coding yielded three general types of data: 1) suggestions for improving academic training, 2) suggestions for improving continuing education or professional development resources, and 3) comments that did not directly address either element of the survey item. Sixty-nine (of 81) respondents provided a written response to question 18 . Twentyfive respondents addressed the first element, 26 addressed the second element, and 12 addressed both elements or provided comments that were not directly related to either element. Some of the open-ended responses were brief, but the majority included substantive content.

After open-ended responses were color-coded by type of data, the researcher created a table to further organize responses. Each comment representing new content was added to a table with three columns: one for content related to academic preparation, one for content related to continuing education, and one for unrelated content. If a comment was similar to a comment already recorded on the table, hash marks were used to keep track of the number of times a similar comment was made. In this way, open-ended comments were tabulated according to the three descriptive codes, and the frequency of each comment was summarized. 
Once open coding was complete, the researcher again returned to the data and began to develop themes; these are broader units of meaning that represented common ideas within the data (Creswell, 2013). Because the coded data table was brief, this second stage of coding —or thematic analysis--proceeded through visual inspection of data and an inductive process that drew on the researcher's personal perspective, the study's conceptual framework, and the words of the respondents themselves in order to identify and label themes (Merriam, 2009). Themes were first identified within each of the three descriptive codes. These themes were then compared for similarities and differences, which resulted in the combination of several codes. Ultimately, five themes were identified that fit the data from all three original descriptive codes; these themes are described in the following section. After thematic analysis was completed, the process and results were reviewed by an advisor with expertise in qualitative research. Peer debriefing is one strategy for strengthening study validity (Creswell, 2013).

\section{Results}

The following sections describe the characteristics of the sample, as well as data related to competency development, perceived effectiveness of academic training, perceived effectiveness of professional development resources, and suggestions for improving academic training and continuing education to better prepare OTs for community-based practice.

\section{Sample Characteristics}

The sample size was 81 . This represented a $16.2 \%$ return rate, although it is not known how many of the 500 potential respondents actually received and read the mailed invitation. Seventy-six respondents (95\%) were women and four respondents $(5 \%)$ were men. One respondent did not indicate gender. Almost eighty percent (79.63\%) of respondents reported that they currently work in a community-based practice setting, and the remaining $20.37 \%$ have 
worked in community-based practice within the past three years. All respondents were occupational therapists, and they represented 36 states. Please see Table 2 for a summary of respondents' educational and practice backgrounds.

Table 2

Study Respondents' Educational and Practice Backgrounds

\begin{tabular}{lcc}
\hline & $\begin{array}{c}\text { Frequency } \\
(\mathrm{N}=81)\end{array}$ & Percent (\%) \\
\hline Bachelor's degree & 36 & 44.44 \\
Master's degree & 35 & 43.21 \\
Entry-level doctoral degree & 2 & 2.47 \\
Post-professional doctoral degree & 8 & 9.88 \\
0-1 years in community-based practice & 1 & 1.23 \\
2-5 years in community-based practice & 15 & 18.52 \\
6-10 years in community-based practice & 17 & 20.99 \\
11-15 years in community-based practice & 8 & 9.88 \\
16-20 years in community-based practice & 19 & 23.46 \\
20+ years in community-based practice & 21 & 25.93 \\
\hline
\end{tabular}

Respondents had a wide range of community-based experience. Over 35\% had experience in home health, but a wide range of other experiences were also represented, including about $14 \%$ who chose the category "other." Responses written in for the "other" category included home modification, mobile outpatient services, wheelchair and durable medical equipment provision, community re-entry for traumatic brain injury, adult day program, 
agency on aging, certified hand therapist, non-profit health organization, and on-site industrial rehabilitation. Please see Table 3 for a summary of the areas of community-based practice in which respondents reported experience.

Table 3

Survey Respondents' Areas of Community-Based Experience

Frequency $\quad$ Percent $(\%)$

$$
(\mathrm{N}=81)
$$

Home health

Ergonomics

Hospice

Wellness and health promotion

Early intervention

Community mental health

Vocational

Group homes

Public health

Other

64

18

15

14

13

13

9

9

4

14
36.99

10.4

8.67

8.09

7.51

7.51

8.09

\section{Competency Development}

Respondents were asked to indicate which professional development strategies they found most effective in developing the unique competencies needed for community-based practice. This question grouping was closely aligned with the study's conceptual framework; competencies were drawn from the work of Scaffa (2014) and strategies were drawn from the 
work of King (2009). In addition, the survey allowed respondents to choose an "other" category if they chose to write in a strategy that was not listed. Few respondents chose this option. Responses given in the "other" category can be found in Appendix D. Response patterns differed for each competency, but in general self-directed learning was the strategy identified most frequently across competencies. Figures 1 through 6 present the patterns of strategy choice (by percentage) for each unique competency.

Figure 1

Most Effective Strategy for Developing Performance Skills

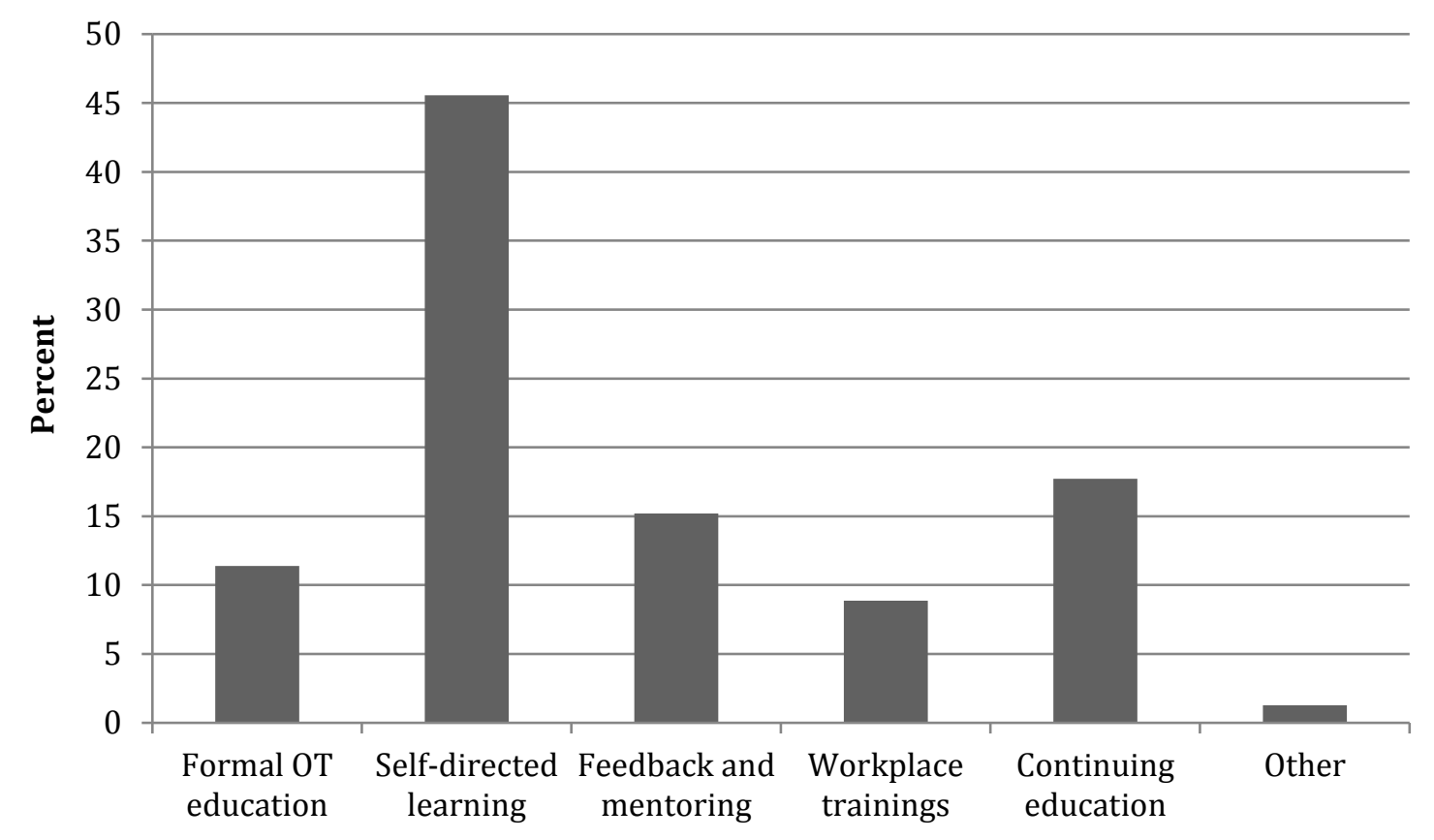

A plurality of respondents (45.57\%) reported self-directed learning to be the most effective strategy for developing the performance skills needed for community-based OT practice. Response rates were much lower for the other four options: continuing education (17.72\%), feedback and mentoring (15.19\%), formal OT education (11.39\%), workplace training (8.86\%), and other (1.27\%). 
Figure 2

\section{Most Effective Strategy for Developing Specific Knowledge}

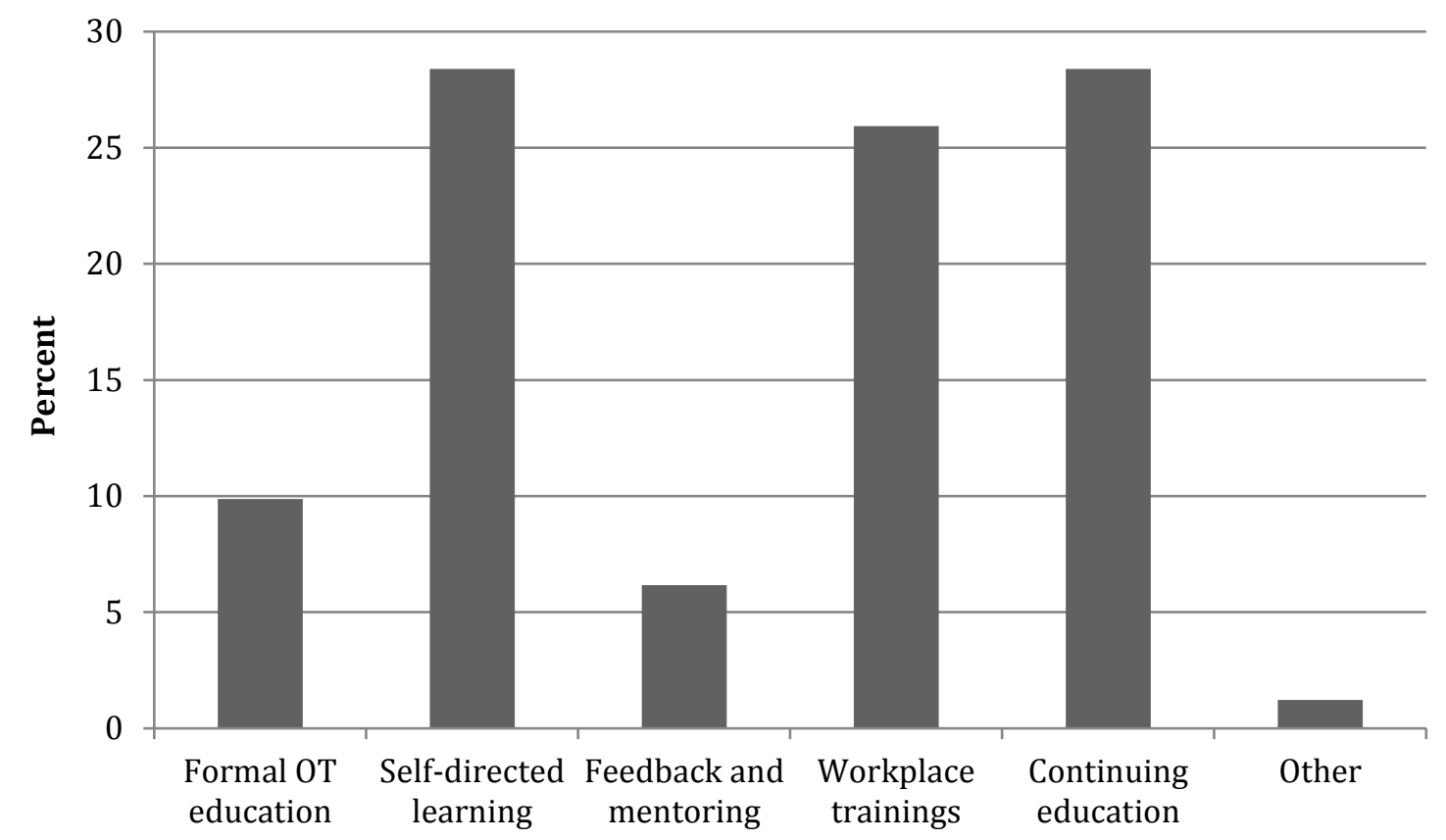

There was a roughly even split between the three strategies chosen as most effective in developing the specific knowledge needed for community-based OT practice: self-directed learning $(28.40 \%)$, continuing education (also $28.40 \%)$, and workplace trainings $(25.93 \%)$. The remaining options were chosen by significantly fewer respondents: formal OT education (9.88\%), feedback and mentoring (6.17\%), and other (1.23\%). 
Figure 3

\section{Most Effective Strategy for Developing Critical Reasoning Skills}

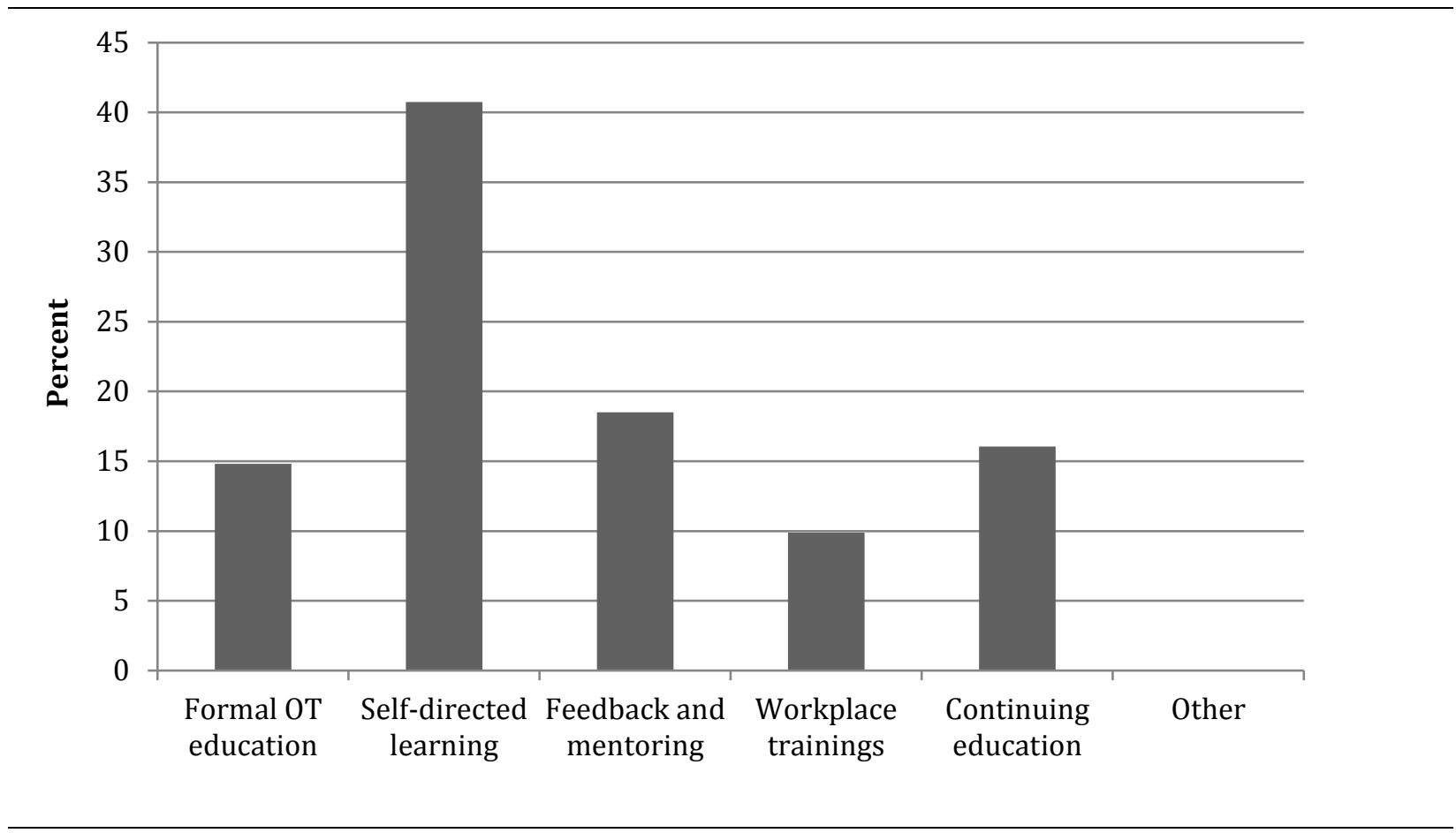

As with performance skills, a plurality of respondents $(40.74 \%)$ reported self-directed learning to be the most effective strategy for developing the critical reasoning skills needed for community-based OT practice. The remaining four options were chosen less frequently, but were chosen at similar rates: feedback and mentoring (18.52\%), continuing education (16.05\%), formal OT education (14.81\%), and workplace trainings $(9.88 \%)$. 
Figure 4

\section{Most Effective Strategy for Developing Ethical Reasoning Skills}

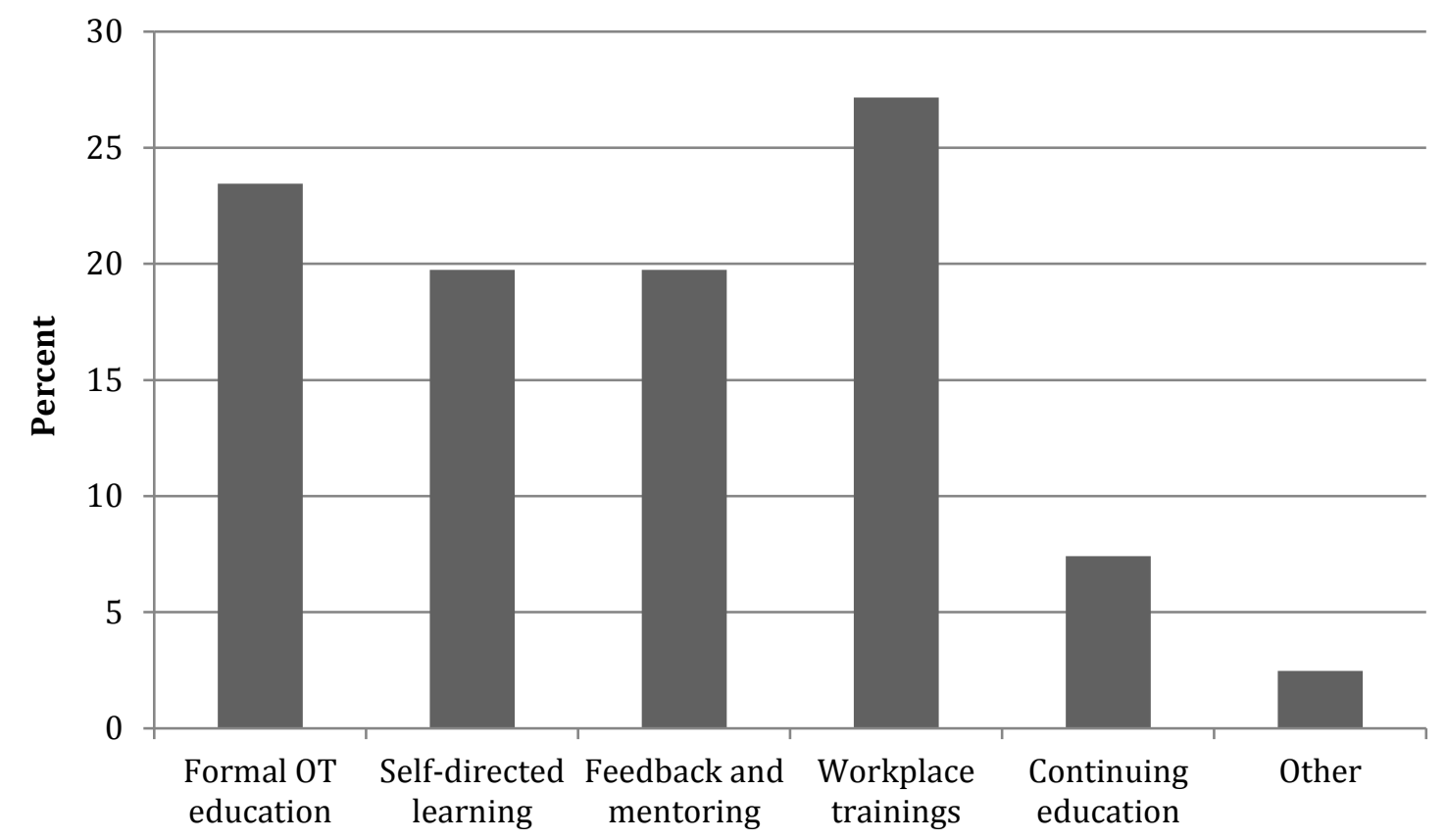

Workplace trainings were reported by $27.16 \%$ of respondents as the most effective strategy for developing the ethical reasoning skills needed for community-based OT practice, followed closely by formal OT education (23.46\%), self-directed learning (19.75\%) and feedback and mentoring (also 19.75\%). Continuing education was selected by $7.41 \%$ of respondents, and other was selected by $2.47 \%$ of respondents. 
Figure 5

Most Effective Strategy for Developing Interpersonal Communication Skills

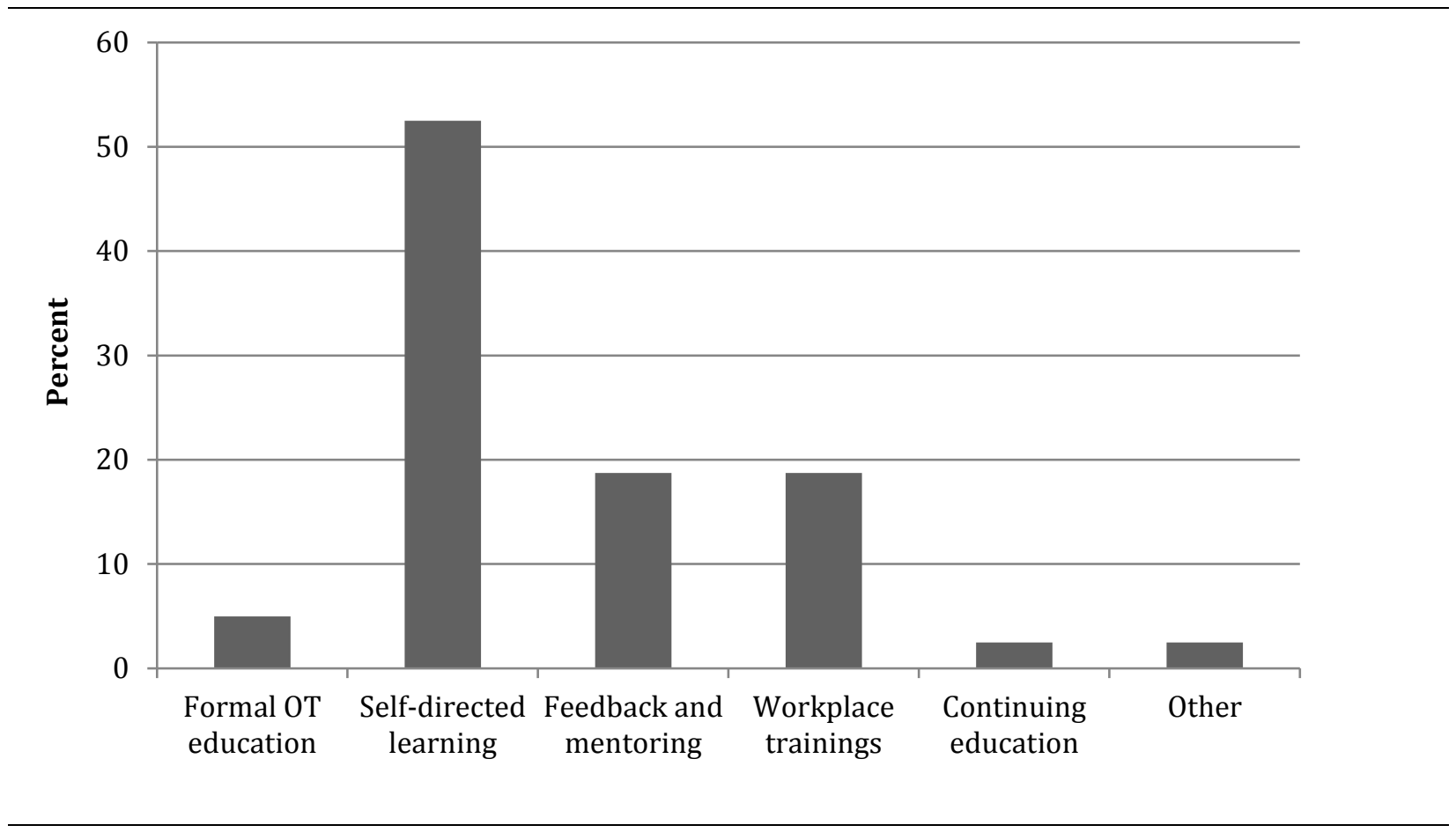

The majority of respondents $(52.50 \%)$ selected self-directed learning as the most effective strategy for developing the interpersonal communication skills needed for communitybased OT practice. Feedback and mentoring, and workplace trainings were each selected by $18.75 \%$ of respondents, followed by formal OT education $(5.00 \%)$, continuing education $(2.50 \%)$, and other (2.50\%). 
Figure 6

\section{Most Effective Strategy for Developing Personal Qualities and Characteristics}

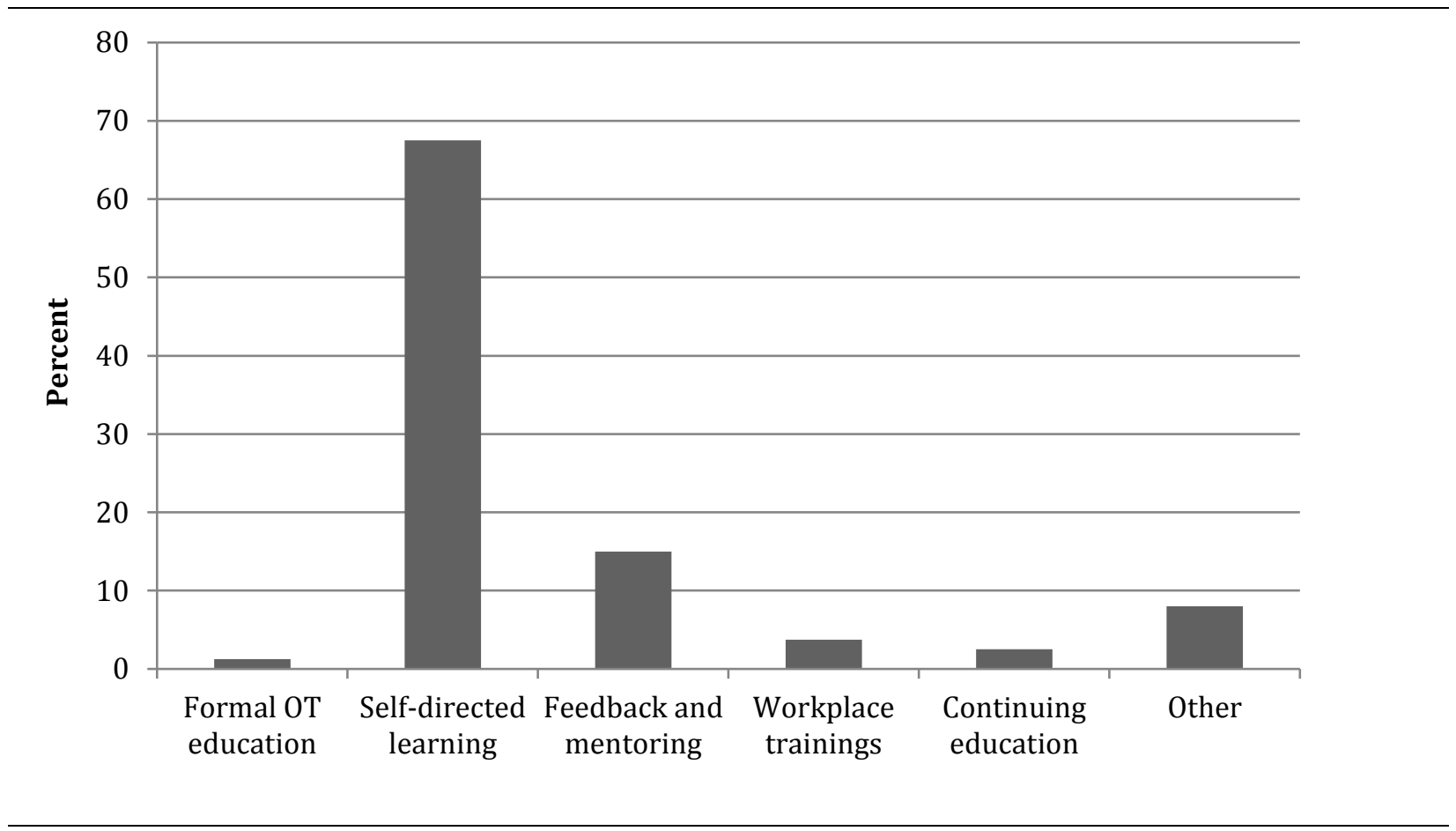

This competency item had the most pronounced results, with the significant majority $(67.50 \%)$ of respondents identifying self-directed learning as the most effective strategy for developing the personal qualities and characteristics needed for community-based OT practice. $15.00 \%$ of respondents selected feedback and mentoring. The remaining options were selected by just a few respondents: other $(10.00 \%)$, workplace trainings $(3.75 \%)$, continuing education (2.50\%), and formal OT education (1.25\%).

\section{Effectiveness of Academic Training and Continuing Education Resources}

Respondents were asked to rate the effectiveness of the preparation for community-based practice that they received through their OT academic training, as well as the effectiveness of current professional development resources for supporting community-based OT. Both items were rated on a 5-point Likert-type scale ranging from very effective (5) to very ineffective (1). 
For both questions the responses centered between "effective" and "average" (see Table 7). The mean for effectiveness of academic training was 3.43 (SD .91) and the mean for effectiveness of current resources was 3.42 (SD .95).

Figure 7

Respondents' Ratings of the Effectiveness of Academic Training and Professional Development Resources

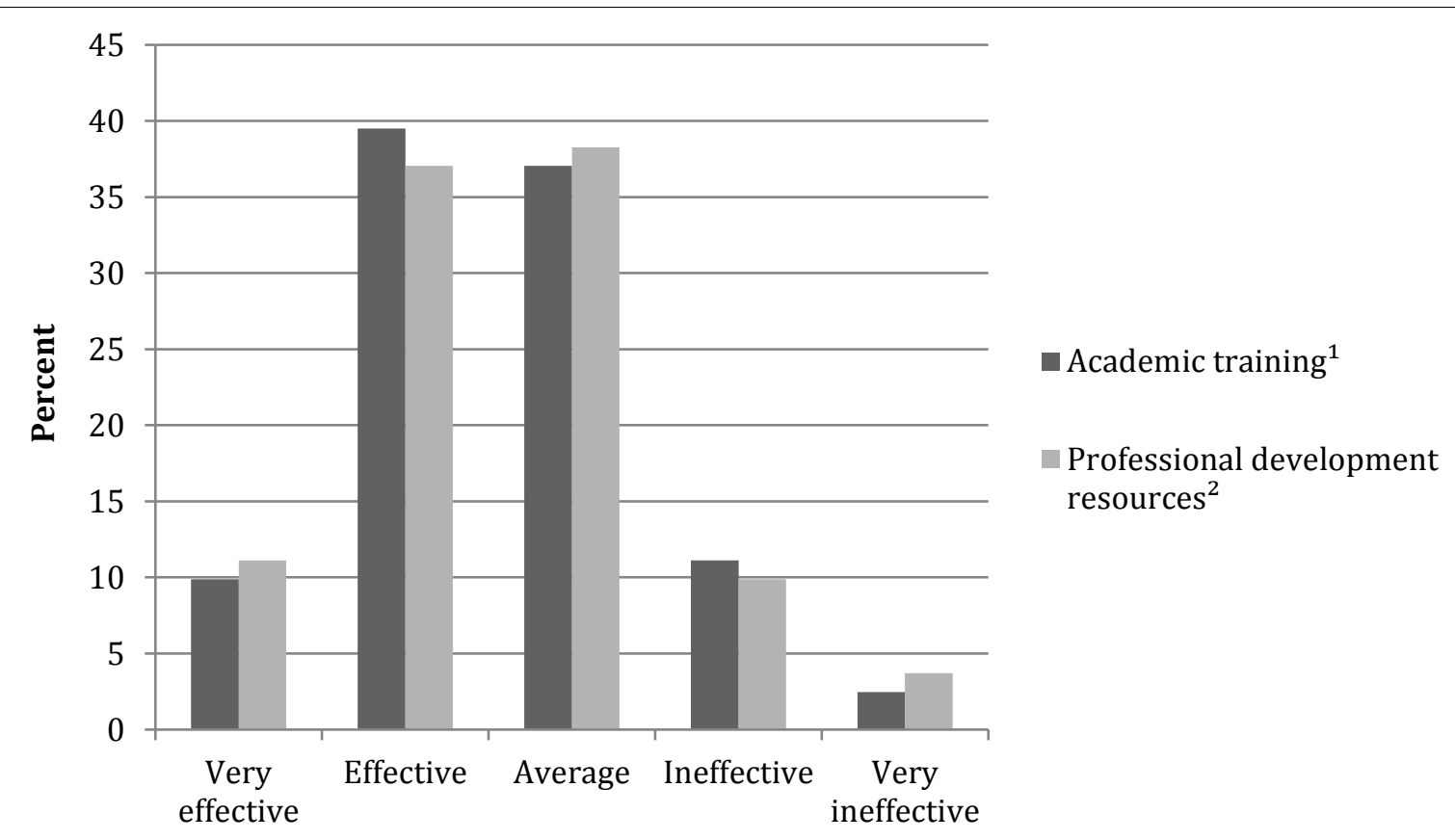

1"How effective was your OT education in preparing you for community-based practice?" 2 "How effective are existing professional development resources (continuing education options, online education, journal and research resources, etc) in improving your skills for communitybased OT practice?" 
Figure 7 shows that most respondents rated their academic training as either average (37.04\%) or effective (39.51\%). Likewise, most respondents rated current professional development resources as either average $(38.27 \%)$ or effective $(37.04 \%)$.

\section{Qualitative Data}

In the survey's final question, respondents were asked to make their own suggestions for improving academic training (see Table 4) and continuing education to better prepare and support OTs in community-based practice (see Table 5). The open-ended comments provided by respondents were more numerous and more in-depth than expected. In order to preserve the diversity of respondents' open-ended responses, findings are presented in a condensed but still comprehensive form. Comments higher in the table were made by more respondents. 
Table 4

Suggestions for Improving OT Academic Preparation for Community-Based Practice

\begin{tabular}{|c|c|c|}
\hline Suggestion & $\begin{array}{l}\text { Frequency } \\
\qquad(\mathrm{n}=69)\end{array}$ & $\begin{array}{l}\text { Percent }(\%) \\
\quad(\mathrm{n}=69)\end{array}$ \\
\hline $\begin{array}{l}\text { Provide more community-based Fieldwork (FW) and/or clinical } \\
\text { experiences }\end{array}$ & 17 & 24.6 \\
\hline $\begin{array}{l}\text { Invite community-based practitioners to provide guest lectures } \\
\text { or to teach courses }\end{array}$ & 9 & 13.0 \\
\hline Include community-based content in curriculum & 4 & 5.8 \\
\hline Teach pharmacology and medication & 3 & 4.3 \\
\hline Provide more home health FW opportunities & 3 & 4.3 \\
\hline $\begin{array}{l}\text { Emphasize evidence-based practice (EBP) for community- } \\
\text { based practice }\end{array}$ & 2 & 2.9 \\
\hline $\begin{array}{l}\text { Increase emphasis on mental health across the curriculum and } \\
\text { in clinical experiences }\end{array}$ & 2 & 2.9 \\
\hline $\begin{array}{l}\text { Increase learning experiences and assignment s that prepare } \\
\text { students for community practice by pushing them outside their } \\
\text { comfort zones }\end{array}$ & 2 & 2.9 \\
\hline $\begin{array}{l}\text { Emphasize well-rounded skills and creativity to prepare } \\
\text { students to address a wide range of client needs and priorities in } \\
\text { various community settings }\end{array}$ & 2 & 2.9 \\
\hline $\begin{array}{l}\text { Increase emphasis on the importance of setting: rural vs. urban } \\
\text { vs suburban }\end{array}$ & 1 & 1.4 \\
\hline Increase awareness of community resources & 1 & 1.4 \\
\hline $\begin{array}{l}\text { Additional suggestions for specific academic content: symptom } \\
\text { management, Certified Aging in Place (CAPS), home }\end{array}$ & multiple & \\
\hline technology and adaptive equipment, ergonomics, taking vitals, & & \\
\hline psychopathology, group leadership and group dynamics, & & \\
\hline $\begin{array}{l}\text { business planning, legislative and regulatory issues, financial } \\
\text { and social issues }\end{array}$ & & \\
\hline
\end{tabular}


While increasing community-based FW and clinical experience was clearly the most frequent suggestion for improving academic preparation, the responses related to improving continuing education were more evenly distributed.

\section{Table 5}

Suggestions for Improving Continuing Education Resources

\begin{tabular}{|c|c|c|}
\hline Suggestion & $\begin{array}{c}\text { Frequency } \\
\qquad(\mathrm{n}=69)\end{array}$ & $\begin{array}{c}\text { Percent }(\%) \\
(\mathrm{n}=69)\end{array}$ \\
\hline $\begin{array}{l}\text { Offer mentorship programs to OTs new to community-based } \\
\text { practice }\end{array}$ & 9 & 13.0 \\
\hline Improve continuing education specific to home health & 5 & 7.2 \\
\hline Provide continuing education on medications & 5 & 7.2 \\
\hline $\begin{array}{l}\text { Increase focus on research, new techniques, and evidence-based } \\
\text { practice (EBP) }\end{array}$ & 5 & 7.2 \\
\hline $\begin{array}{l}\text { Provide more continuing education on environmental and home } \\
\text { modification and technology }\end{array}$ & 4 & 5.8 \\
\hline $\begin{array}{l}\text { Provide more advanced continuing education specific to } \\
\text { community-based practice }\end{array}$ & 4 & 5.8 \\
\hline $\begin{array}{l}\text { Provide continuing education on reimbursement and regulatory } \\
\text { issues }\end{array}$ & 3 & 4.3 \\
\hline $\begin{array}{l}\text { Work first with an experienced team before moving into home } \\
\text { health or other community-based practice }\end{array}$ & 2 & 2.9 \\
\hline $\begin{array}{l}\text { Employers and agencies should provide financial support for } \\
\text { continuing education }\end{array}$ & 2 & 2.9 \\
\hline $\begin{array}{l}\text { Employers and agencies should provide free in-house } \\
\text { continuing education }\end{array}$ & 2 & 2.9 \\
\hline $\begin{array}{l}\text { Create increased support for OTs who work in non-traditional } \\
\text { and emerging areas of practice }\end{array}$ & 2 & 2.9 \\
\hline $\begin{array}{l}\text { Create more online options such as discussion forums and } \\
\text { interactive workshops }\end{array}$ & 2 & 2.9 \\
\hline
\end{tabular}


Table 5 (continued)

Additional suggestions for specific continuing education multiple content: community resources, gait training and functional mobility, taking vitals, documentation, time management, wound care, symptom management and treatment of specific conditions, health promotion, ergonomics, regulations, workplace injury, body mechanics, durable medical equipment, goal-writing, leadership, communication, and ethics

In addition to the many comments about academic preparation and continuing education summarized in Table 4 and 5, there were 14 addition comments that did not directly address the survey question but nonetheless provided interesting information. Several respondents commented that not all OTs are suited to community-based practice, and that community-based practice requires some skills that cannot be taught. Several respondents expressed the opinion that community-based practice is not appropriate for new graduates because it requires a level of skill and independence that new therapists lack. Finally, there were a handful of written comments appraising current continuing education options. Three respondents wrote that many continuing education courses are too generic, too simplistic, or do not reflect the realities of working in the community. On the flip side, two respondents stated that there are abundant opportunities for continuing education, and said they felt satisfied with their ability to find options that met their needs as community-based OTs. 


\section{Qualitative Analysis}

Analysis of the qualitative data yielded the following five themes. Each theme addressed the research question "what additional professional development resources do respondents feel they need in order to develop expertise in their areas of practice?" Themes emerged from the synthesis and analysis of coded data described previously as: 1) suggestions for improving academic training, 2) suggestions for improving continuing education or professional development resources, and 3) comments that did not directly address either element of the survey item. Representative comments are provided to illustrate each theme.

\section{Theme 1: Draw more on the experience of expert clinicians in educating students.}

By far the most frequent suggestion made in response to survey question 17 was that OT programs should increase community-based fieldwork (FW) and clinical opportunities; 22 respondents made this suggestion in some form. Also in this category were suggestions for the increased use of guest lecturers and faculty with community-based experience. The data within this theme suggest that respondents feel academic programs need to do more to take advantage of the expertise of those clinicians who are currently working in community-based settings. One respondent wrote:

It would be really great if there were more affiliations and clinical experiences for students in home health. OT is a perfect fit for this setting yet it seems like most students are not directly exposed. I personally would like to have the opportunity to guest lecture about home health care as I love it and I think I could generate enthusiasm in students for this important treatment environment (Respondent 33)

Theme 2: Increase mentorship and support within work settings. While increased community-based FW was the most common suggestion related to academic training, increasing 
the availability of mentorship was the leading suggestion related to professional development for OTs already in practice. Fourteen respondents spoke to different aspects of the need for improved support in work settings. Nine respondents suggested the need for more mentorship programs, citing the importance of learning from experienced practitioners before entering community-based practice. For example, Respondent 74 wrote that "my OT education provided the seeds to develop as an OT. In my opinion, to excel in community settings one needs prior experience as an OT with a few seasoned and devoted OT mentors.” Respondent 5 agreed, noting the need for mentoring because "home health is a very 'alone' type of work place, and I've found communication with colleagues to be vital in sorting things out." Four respondents also suggested that employers should do more to pay for continuing education, or should provide free continuing education on-site.

Theme 3: Increase recognition and respect for community-based practice. Eight respondents touched on this theme, and in some ways it was also an underlying assumption for many of the respondents who recommended increased fieldwork, guest lectures, and other forms of exposure to community-based practice. Respondent 13 wrote that academic programs should "recognize that many community-based practitioners are providing non-clinical OT-applying the principles and practices in new ways with new populations." Several respondents commented specifically on the need for greater emphasis on training for mental health practice, with Respondent 40 commenting that "most students I have supervised or talked to know very little about mental health in the community."

Theme 4: Increase education and training for specific content. Along with a need to validate the role of OTs in community-based practice, many respondents had specific suggestions for content that should be included either in academic curricula or continuing 
education courses. Twelve respondents made suggestions for content to enhance academic training, and 18 respondents made suggestions for improving continuing education to make it more relevant to community-based OTs. The content suggestions were wide ranging; see summaries in Table 4 and Table 5. Content areas cited by multiple respondents included medications, ergonomics, legislation and regulations, insurance, documentation, and equipment. The fact that so many respondents had specific suggestions for educational training is consistent with the comments of the four respondents who wrote that they find current educational resources inadequate to the specialized needs of community-based practice, particularly for those OTs who are experienced practitioners (as many who took this survey were). Respondent 39 stated that "So much of the continuing education available is so generic," and Respondent 26 wrote:

Continuing education specifically for OTs in ergonomics and health promotion is sorely lacking, especially for those of us with advanced skills who are looking at further growth within the profession...There needs to be more CE especially advanced level, more networking, more recognition of us 'out of the norm' therapists.

Theme 5: Increase evidence-based practice resources. Fewer respondents addressed this theme than some of the others, but it was nonetheless significant. Seven respondents directly commented on the need for more emphasis on research specific to community-based practice. Two of these comments related to academic training; five related to continuing education, such as the comments of Respondent 63 who recommended "a training focus on "evidence-based practice' in an area without a lot of academic literature available in order to boost confidence and decision-making." Theme 5 had some cross-over with Theme 4; there were a number of comments that suggested specific educational content in the context of new research. For 
example, Respondent 11 suggested "on-line, interactive learning workshops which focus on new research, new ideas/techniques that can be shared for specific diagnosis [sic]," and Respondent 19 identified the need for "specific evidence-based assessments for the community."

\section{Summary of Results}

Data from 81 completed surveys were included in the study. Respondents were mostly women, and over $80 \%$ reported six or more years of experience in community-based practice. Most held either a bachelor's degree or a master's degree, with an even split between these two levels of education. Respondents reported a wide range of community-based practice experience; the most frequently reported area was home health, followed by ergonomics, hospice, and wellness/ health promotion.

Findings correspond to the study's three research questions. The first aim of this study was to identify which professional development strategies community-based OTs find most effective for developing the specific competencies that have been identified as unique to community-based OT practice. Different strategies were rated more and less effective for different competencies, but overall self-directed learning was clearly the most-chosen strategy. Formal OT education (“OT school”) was selected by relatively low percentages of respondents in every competence category except ethical reasoning.

The study's second aim was to explore respondents' perceptions of the effectiveness of their OT academic training and existing professional development resources. Although formal OT education was not frequently selected as an effective strategy for the development of unique competencies in the questions addressing the first aim, the majority of survey respondents did rate their OT education as either "average" or "effective" in preparing them for communitybased practice. The majority of respondents also rated existing professional development 
resources as either "average" or "effective" in developing the skills they need for communitybased practice.

The final aim of the study was to gather qualitative data about respondents' suggestions for improving academic training and continuing education options. The majority of respondents (69/81) provided open-ended responses to the survey item addressing this research question, and those responses generally included substantial content. Increasing community-based FW and other clinical experiences was by far the most frequent suggestion related to academic training. Respondents also suggested improving OT education by inviting community-based OTs to provide guest lectures, and by increasing content specific to community-based practice within OT curricula. Suggestions for improving continuing education resources included increased access to mentorship programs, increased continuing education for home health, increased continuing education on medications, increased resources promoting research and evidencebased practice, and others. Data analysis yielded five themes that address the study's third aim:

1. Draw more on the experience of expert clinicians in educating students

2. Increase mentorship and support within work settings

3. Increase recognition and respect for community-based practice

4. Increase education and training for specific content

5. Increase evidence-based practice resources

Interpretations of the quantitative and qualitative data--including connections to the literature, to the study's conceptual framework, and to practice--will be explored in the following chapter. 


\section{CHAPTER 5}

\section{CONCLUSION}

The purpose of this study was to explore the strategies used by community-based occupational therapy (OT) practitioners to develop the competencies that are unique to community-based OT practice. The aims of the study were 1) to discover which professional development strategies community-based occupational therapists (OTs) find most effective to develop the specific competencies that have been identified as unique to community-based OT practice, 2) to examine respondents' perceptions of the effectiveness of their academic training and of current professional development resources, and 3) to explore respondents' suggestions for improving academic training and continuing education for community-based OT practice.

Data were gathered through a national electronic survey that targeted OTs with current or recent experience in community-based practice. The survey instrument was designed by the researcher using QuestionPro software; it was pilot tested and revised before being implemented. All data were gathered electronically and compiled within QuestionPro. Quantitative analysis consisted of descriptive statistics including frequency, percent, mean, and standard deviation; data were represented narratively and graphically. Qualitative analysis consisted of an inductive process of coding and theme development, based on Creswell's (2013) "data analysis spiral" (p. 182).

In total, 81 surveys were analyzed for quantitative content and 69 surveys were analyzed for qualitative content. Almost all (95\%) of the study participants were women, and most held either a bachelor's degree (44\%) or a master's degree (43\%). About $80 \%$ reported working currently in community-based practice; practice experience was wide ranging, with home health being the most common practice area. 


\section{Interpretation of Findings}

This section includes discussions and conclusions specific to each of the three research aims. This section references both quantitative and qualitative data described in detail in Chapter 4, and integrates scholarly literature and elements of the conceptual framework described previously.

\section{Strategies for Competency Development}

The study's first aim was to discover which professional development strategies community-based OTs find most effective for developing the competencies that have been identified as unique to community-based OT practice. Scaffa's 2014 framework of competencies for community-based and emerging OT practice defined the competency areas explored in this study: (a) knowledge, (b) performance skills, (c) critical reasoning, (d) ethical reasoning, (e) interpersonal abilities, and (f) traits, qualities, and characteristics. King's 2009 framework for the development of expertise provided the basis for the professional development strategies that respondents could select: (a) formal OT education, (b) self-directed learning, (c) feedback and mentoring, (d) workplace trainings, and (e) continuing education. Respondents could also select "other," to allow for responses that did not fit within the study's conceptual framework. The following sections discuss each of the six unique competencies separately, and provide interpretations and comparisons of the data, with connections to the current literature and the conceptual framework.

Developing performance skills competencies. Performance skills competencies for community-based practice include client-centered assessment and intervention, evidence-based practice, team collaboration, activity analysis, and consultation (Scaffa, 2014). Study results showed that about $46 \%$ of respondents rated self-directed learning as the most effective strategy 
for developing these competencies; no other strategy came close. Formal OT education was selected by only about $11 \%$ of respondents, which is notable because performance skills are foundational abilities that span areas of practice and are therefore emphasized in OT accreditation standards as essential for entry-level competence (Holmes \& Scaffa, 2009a). For example, client-centered assessment and intervention principles should apply equally in a hospital, a school, or a client's home. Therefore it might be expected that OTs would more highly rate the influence of their academic training on this competency area. The fact that they did not may indicate that respondents did not perceive their academic training in performance skills as highly relevant to community-based practice.

It is also possible that respondents self-defined this category in a different way than was intended, or that perceived relevance of one's formal education is simply reduced after many years in practice. Almost $68 \%$ of respondents had been OTs for 20 years or more, and the majority of respondents reported ten or more years of experience in community-based practice. This was an experienced sample, which may account in part for why self-directed learning rated so highly across competencies. Many respondents would likely fit Benner's (1984) description of an expert clinician: a clinician with deep experience and a flexible, intuitive understanding of clinical situations, who no longer needs to rely strictly on didactic knowledge. King (2009) cited the work of Phillips, Kline, and Sieck (2004) in pointing out that expert clinicians are more likely to learn experientially--through engagement, feedback, and reflection-whereas novice clinicians value rules, directions, and concrete instruction. Five respondents in this study commented on the importance of experience. For example, Respondent 22 wrote, "I don't know if this [community-based practice] is something you can teach. I think it is something you learn from experience." 
Developing knowledge competencies. According to AOTA, knowledge is the information required for one's roles and responsibilities (AOTA, 2010b). Knowledge competencies for community-based practices include principles of occupation-based practice, principles of client-centered practice, principles of public health, applying theoretical models to evaluation and intervention, program development, and community systems (Scaffa, 2014). Results showed that three strategies were rated about equally in effectiveness for developing these competencies: self-directed learning (28.4\%), continuing education (also $28.4 \%$ ), and workplace trainings (25.9\%). Formal OT education was selected by about $10 \%$ of respondents. Because knowledge competencies relate more specifically to a particular role and setting than do performance skills, it is understandable that respondents might value strategies that directly convey specific knowledge, such as workplace trainings and continuing education. The low rating for formal OT education is consistent with respondents' open-ended comments, which reflected a perceived need for additional specific knowledge content within OT curricula.

Developing critical reasoning competencies. Critical reasoning competencies for community-based practice include holistic reasoning, problem solving, translating theory to practice, thinking outside the box, and using sound judgment (Scaffa, 2014). Similar to the results for performance skills, over $40 \%$ of respondents rated self-directed learning as the most effective strategy for developing these competencies, with other strategy options a distant second. Formal OT education was selected by about $15 \%$ of respondents. Again, this may in part reflect the level of experience of many of the OTs sampled. Expert clinicians are able to grasp a situation in its entirety and focus on the key aspects (Benner, 1984). Because they often value intuitive expertise gained over time, experienced OTs may place a higher value on self-directed learning than on formal academic instruction. Carrier et al (2010) found that practice context has 
a particularly strong impact on community OTs' clinical reasoning. This may further explain why respondents report that critical reasoning competencies are developed most effectively through self-directed learning: these competencies are highly influenced by the setting in which one practices.

Developing ethical reasoning competencies. Ethical reasoning competencies for community-based practice include self-assessment of one's strengths and needs, pursuing professional development, and understanding and using principles of social and occupational justice (Scaffa, 2014, p. 9). In this competency area respondents chose four effective strategies, all rated fairly similarly: workplace trainings (27.1\%), formal OT education (23.4\%), selfdirected learning (19.8\%), and feedback and mentoring (also 19.8\%). This was the highest rating for formal OT education among all six competencies. The even spread of responses in this category suggests that there was no one strategy recognized as most effective in promoting ethical reasoning. Ethical competencies are a component of the AOTA Standards for Continuing Competence and the AOTA Code of Ethics, and good ethical standing is required to maintain registration and licensure. Therefore, this may be a competency that respondents were more likely to associate with their formal OT education, although respondents also found other strategies effective in developing ethical competencies. King's 2009 framework of professional development strategies identifies three types of learning based on the literature: experiential, instructional, and observational (p. 188). According to King (2009), experiential learning is comprised of direct experience, feedback, and reflection (p. 190). It may be that the development of ethical reasoning competencies fits particularly well with the experiential learning component of professional development. 
Developing interpersonal competencies. Interpersonal competencies for communitybased practice include active listening, communicating to diverse audiences, establishing relationships with diverse stakeholders, networking, demonstrating cultural competence, and negotiating (Scaffa, 2014, p. 9). Results showed that $52.5 \%$ of respondents rated self-directed learning as the most effective strategy for developing these competencies. A much smaller percentage (about 19\%) selected workplace trainings and continuing education. Formal OT education was selected by only four respondents (5\%). Although the ACOTE Standards include a requirement for demonstrating therapeutic use of self (ACOTE, 2011, B.5.7), interpersonal communication is one of those soft skills that are not often explicitly taught (King, 2009). The results are consistent with the perception that interpersonal skills either arise through selfdirected learning, such as self-reflection, or are inherent in the person.

The results_-from an experienced sample_-also support the idea that interpersonal communication skills develop with experience. In a 2013 systematic review of the knowledge, skills, and professional behaviors needed by occupational and physical therapists in work-related practice, Adams et al. found that "the skill that received the most support in the literature was communication" (p. 83). They speculated that vocational practice requires mature, experienced clinicians who can adjust their communication styles to the needs of diverse stakeholders and situations. For example, in this area of community-based practice the client could be an employer, an insurance provider, or a legal representative, not just the injured employee (Adams et al., 2013). Similarly, Holmes and Scaffa (2009a) noted that the interpersonal skills identified in their study of competencies might be reflective of "advanced practitioners" with the ability to thrive in challenging roles (p. 86). 
Developing traits, qualities, and characteristics. Traits, qualities, and characteristics for community-based practice include adaptability, independence, confidence, ability to step outside the medical model, tolerance for ambiguity, and creativity (Scaffa, 2014, p. 9). Results showed that self-directed learning was far and away considered the most effective strategy for developing these competencies, as rated by almost $68 \%$ of the sample. Formal OT education was selected by only one respondent. This is the one competency category from Scaffa's framework that does not have a parallel in the AOTA Standards for Continuing Competence; this category arose directly from the study by Holmes and Scaffa (2009a).

Continuing competence is defined by AOTA as "a dynamic and multidimensional process in which the occupational therapist and occupational therapy assistant develop and maintain the knowledge, performance skills, interpersonal abilities, critical reasoning, and ethical reasoning skills necessary to perform current and future roles and responsibilities within the profession" (AOTA, 2010b, para. 1). Although clinicians in the Holmes and Scaffa study identified personal traits as a necessary competency for community-based OT, AOTA does not designate this as an area for ongoing professional development. This suggests that traits, qualities, and characteristics either exist naturally, as suggested by Respondent 7, who wrote "not all people are suited to being as independent as you have to be [in community-based practice]," or perhaps just develop with time and experience. King (2009) noted the need for more emphasis on actually teaching and supporting the development of soft skills, since these skills have such an impact on clinicians' ability to serve clients in diverse and complex settings.

One difference between this study and previous research by Holmes and Scaffa (2009a) is that participants in that study associated the traits and qualities of community-based OTs with those of entrepreneurs and leaders. That theme did not arise in the qualitative data of this study. 
It may be that the design of the current study (survey) did not lend itself to revealing this connection. It may also be that the two studies had different sample characteristics: while most respondents in the current study were clinicians, three quarters of participants in the Holmes and Scaffa study were either faculty members or private business owners. This could account for the fact that participants in the Holmes and Scaffa study felt that community-based OTs need ongoing professional development opportunities to develop leadership and entrepreneurial skills, while respondents in the current study focused their suggestions on clinically-based professional development.

\section{Effectiveness of Academic Training and Current Professional Development Options}

The study's second aim was to examine respondents' perceptions of the effectiveness of their academic training and of current professional development resources. Previous studies have resulted in recommendations for specific student preparation (ACOTE, 2011; Adam et al., 2014; Hanft \& Anzalone, 2001; Holmes \& Scaffa, 2009a) and for ongoing professional development opportunities for clinicians (King, 2009; Holmes \& Scaffa, 2009a; Kendall, et al., 2009). Because formal OT education and various forms of professional development were strategies explored in relation to competency development, it was also important for this study to get a snapshot of respondents' thoughts about their own educational preparation, as well as the professional development options available to them currently.

As described in Chapter 4 , over $75 \%$ of respondents rated their own academic preparation as either average or effective. Only $10 \%$ rated it very effective, and about $14 \%$ rated it ineffective or very ineffective. These results are consistent with the fact that formal OT education was not identified as the most effective strategy for any of the six competencies addressed. Respondents provided many specific suggestions for improving academic training 
however, and this suggests that there was a perceived need among respondents for OT curricula to more directly address the specific knowledge and skills needed to practice in the community. This result was consistent with previous studies that have identified a range of content areas that could be more fully addressed during OTs' academic preparation, including clinical experience in the community, documentation skills, creativity, self-directed learning, community collaboration, program development, entrepreneurship, clinical reasoning, and site-specific knowledge (Adam et al., 2014; Hanft \& Anzalone, 2001; Holmes \& Scaffa, 2009a; Ramsey, 2011).

The results for professional development effectiveness were very similar to those for academic preparation. About $75 \%$ of respondents rated current professional development resources as either average or effective. Eleven percent said they were very effective, and over $13 \%$ found them ineffective or very ineffective. Professional development options (including workplace trainings, feedback and mentoring, and continuing education) fared better statistically than formal OT education in rated effectiveness for developing competencies. However, there was still only one competency area (out of six) where professional development strategies (in this case workplace trainings) were rated more highly than self-directed learning. So again, although respondents seemed reasonably satisfied with the professional development options available, ultimately these options were deemed less effective than their own self-directed learning in almost every competency category. This suggests an opportunity for employers and continuing education providers to evaluate and strengthen the resources provided to OTs in community-based practice.

The findings related to the second aim can be interpreted in more than one way. First, it may be that academic training and professional development resources do not fully meet the 
needs of OTs in community-based practice (Hanft \& Anzalone, 2001; Holmes \& Scaffa, 2009a; Wood et al., 2013). There were several comments that noted a lack of relevant continuing education options, particularly for advanced clinicians. For example, Respondent 56 identified the need for continuing education courses that go beyond basic information to really address the complexities of the home health environment:

I find that CE courses lack reality. They are often based on best case scenario. But insurance and resources often dictate success in home care settings, so adjusting courses to incorporate these realities would make the information more useful instead of frustrating.

This comment is consistent with the previous finding that community-based OTs tended to use different dimensions of clinical reasoning simultaneously, and that reasoning was strongly impacted by practice setting (Carrier et al., 2010).

Second, it may be that since most of the respondents were experienced OTs, they were more likely to learn through engagement, feedback, and reflection (King, 2009). This could explain why most respondents selected self-directed learning as the most effective strategy, since self-directed learning includes the experiential elements of development most likely to serve the needs of these expert clinicians. In addition, it may also be more important to utilize self-directed learning when one is in an advanced area of practice, since advanced practice often requires specialized skills that are beyond entry-level education.

Third, it could be that respondents' perceptions of effectiveness are skewed by their years of experience. This could be particularly true for academic training, since accreditation standards and OT curricula are always changing. The experience that some respondents had in school years or decades ago may not be the same as the experience of new OT graduates in 2017. 


\section{Suggestions for Improving Academic Training and Continuing Education}

The study's third and final aim was to explore respondents' suggestions for improving academic training and continuing education for community-based OT practice. This aim was addressed through the compilation and analysis of qualitative data, in the form of open-ended survey comments. Five themes emerged from this process: 1) draw more on the experience of expert clinicians in educating students, 2) increase mentorship and support within work settings, 3) increase recognition and respect for community-based practice, 4) increase education and training for specific content, and 5) increase evidence-based practice resources.

Qualitative responses supported the premise that because some community-based competencies are unique, there may also be a need for some academic preparation and continuing education that is tailored to community-based OT practice. The specific suggestions made by respondents fit well within the study's conceptual framework, including the competency framework of Scaffa (2014) and the strategy framework of King (2009). The 21 professional development strategies identified by King each addressed one or more of three types of learning: experiential, instructional, and/or observation. The following sections discuss how the qualitative data align with this aspect of the conceptual framework. It should be noted that many of the strategies in King's framework incorporate more than one learning type, and the same is true for the data described below.

Experiential learning. Most of the self-directed learning strategies discussed in the literature are based on principles of experiential learning (King, 2009). As noted previously, experiential learning consists of direct experience, feedback, and self-reflection (King, 2009). The most frequent type of comment in this category was the suggestion for increased access to mentorship opportunities. Nine respondents commented specifically on the need for better 
mentorship and feedback, citing the complexity of the community practice environment and the need for expert guidance even once one is in practice. Other respondents wrote more generally of the importance (and necessity) of learning by experience. For example, one respondent wrote about the importance of job-specific training: "I need to be able to train my replacement and almost nobody does the work that I do, so hiring 'off the street' would be difficult" (Respondent 65). Also in this category were several comments that touched on the importance of teaching creative thinking and reflection in action (Schon, 1983), such as "provide experiences that require students to go outside their comfort zones with the environment, dealing with families, and learning to be flexible at a moment's notice" (Respondent 67).

Instructional learning. Instructional learning is based on the sharing and receiving of information (King, 2009). The most frequent type of comment in this category was the suggestion for specific educational content, either for academic training, continuing education, or both. As noted in Chapter 4, respondents suggested a broad range of specific topics: medications, ergonomics, mental health, legislation and regulations, insurance, documentation, community resources, equipment, research, and many more. These data suggest that respondents believed there is unique information that they need in community-based practice, and this information is not being provided fully through existing educational training and resources. The sheer volume and depth of responses to the survey's final question is some indicator of respondents' interest. Dillman et al. (2014) noted that it can be difficult to motivate respondents to answer open-ended questions at the end of a survey, but that did not seem to be the case here.

Observational learning. Observational learning involves modeling the behaviors of others (King, 2009), and by far the most frequent type of comment in this category was the suggestion for increased community-based fieldwork (FW). While FW incorporates experiential 
and instructional learning as well, it is the opportunity to observe and model an expert clinician that is at the heart of the FW experience. This finding was consistent with previous studies that have recommended community-based FW to increase awareness of practice options and better prepare students to enter less traditional settings (Adam et al, 2014, Hanft \& Anzalone, 2001, Holmes \& Scaffa, 2009a, Holmes \& Scaffa, 2009b; Ramsey, 2011). There is clearly support among community-based clinicians and researchers for more FW opportunities, and several studies have suggested the efficacy of non-traditional FW placements (Dillon, Dillon, King, \& Chamberlin, 2007; Gat \& Razon, 2014; Schaber, 2010). However, incorporating more community-based FW into OT education can be challenging due to the limited number of community-based OTs to serve as supervisors (Holmes \& Scaffa, 2009b) and the need to meet specific accreditation standards.

\section{Implications}

Many scholars have called for additional research to better understand the complex issues surrounding community-based practice and emerging areas of practice (Adam et al., 2013; Carrier et al., 2010; Holmes \& Scaffa, 2009a; Holmes \& Scaffa, 2009b; Ramsey, 2011; Wood et al., 2013). Since there has been no previous research into competency development for community-based OT, it is hoped that the current study may shed some preliminary light on this topic. The study has several significant limitations, but nonetheless succeeded in gathering information from a targeted sample of 81 community-based OTs from across the country in order to better understand which strategies respondents found most effective for developing the unique competencies needed to provide OT services in community-based settings. 


\section{Application to OT Academic Education}

The results of this study indicate that most respondents did not consider formal OT education a highly effective strategy for the development of specific competencies needed for community-based practice. While there can be several interpretations of this result, one interpretation is that OT curricula may not be fully addressing the preparation needs of practitioners who work in community-based settings such as home health, vocational services, early intervention, and community mental health. It should be noted however that many respondents in this study received their formal OT education years ago, and curricula have changed in that time. The current accreditation standards include a number of standards specifically related to community practice (ACOTE, 2011), and Scaffa et al. (2014) noted that that this reflects an increased focus on preparing OT students for non-traditional areas of practice. However, it remains unclear whether academic programs are meeting these standards in ways that are truly effective for supporting community-based practice.

While few respondents selected formal OT education as the most effective way to develop community practice skills, the majority still rated their own OT education as either average or effective. This might reflect an underlying assumption about the level of preparation that one can expect from entry-level education. The ACOTE (2011) standards state that a graduate of an accredited masters program must "be educated as a generalist with a broad exposure to the delivery models and systems used in settings where occupational therapy is currently practiced and where it is emerging as a service" (preamble, p. 1). While there is no definition of an OT generalist, it may be that community-based practice-with its many complexities and its need for independence and adaptability_requires some advanced practice 
skills that are different from those required in institutional settings such as hospitals, schools, and nursing homes.

Previous studies have concluded that community-based OTs need to develop postgraduation skills in areas such as leadership, marketing, business management, program development, (Holmes \& Scaffa, 2009a; Holmes \& Scaffa, 2009b). It may therefore be understandable that formal OT education was not identified as the most effective strategy for building community practice competencies. The ratings of respondents may simply reflect the reality of the professional development process, which should be recognized as a lifelong responsibility for examining and strengthening one's competence (AOTA, 2010b). In other words, respondents may have been reasonably satisfied with their formal OT education, while at the same time recognizing a need for continuing to develop their skills to meet the complex demands of community-based practice, just as OTs must in other advanced areas of practice. This does not mean that OT programs should not continue to strive to better prepare students for all areas of practice, but it may help to explain the survey's results.

\section{Application to Professional Development and Continuing Education}

Three professional development strategies were addressed in the survey items related to competence development: continuing education, workplace trainings, and feedback and mentoring. While these strategies were generally selected as "most effective" at lower rates than was self-directed learning, these strategies were nonetheless deemed "most effective" much more frequently than was formal OT education. This suggests that community-based OTs look to professional development activities to strengthen skills that they may (or may not) have learned during their academic preparation, and to build new skills. According to AOTA (2010b), “continuing competence is maintained through self-assessment of the practitioner's capacities" 
(p. S103), which means practitioners must take an active role in identifying and addressing their own competence needs. Several respondents in the current study commented on the lack of continuing education resources to meet the needs of community-based OTs, particularly those with advanced skills. Advocacy for more mentorship opportunities was also a common thread in this study, as it has been in previous research (Holmes \& Scaffa, 2009a; Ramsey, 2011). There is little in the OT literature specific to mentorship for practitioners, and King (2009) noted that while mentorship within college and university settings is common, mentorship has been largely overlooked as a professional development strategy for clinical practice. King (2009) also noted that while productivity requirements combined with the solitary nature of much communitybased practice make mentorship more difficult, it is not impossible to implement this strategy. This study offers support for the importance of developing innovative models for feedback and mentorship that can work in community-practice settings.

\section{Key Recommendations for Action}

The recommendations for action fall into two categories: those intended to strengthen academic curricula to better support the preparation of community-based OTs, and those intended to strengthen professional development options to more effectively meet the diverse needs of community-based OTs.

\section{Recommendations for OT Programs}

1. Explore options for providing more community-based FW. While this can be challenging due to limited resources and accreditation requirements, it may be well worth the effort. This recommendation was far and away the most common suggestion from respondents in this study. 
2. Strengthen relationships with local community-based OTs. These clinicians not only have the potential to serve as FW supervisors, but may also be interested in sharing their expertise as guest lecturers, adjunct instructors, partners for student learning activities, collaborators for service-learning projects, collaborators for community-engaged scholarship activities, or panelists/speakers for special events.

3. Evaluate course content to be sure that knowledge, performance skills, clinical reasoning, and ethical reasoning specific to community-based practice are included. This could include strengthening assignments that already exist to give them a community practice spin or designing new projects to emphasize evidence-based competencies.

4. Evaluate ACOTE standards and their associated assessment methods. This recommendation could be implemented at the level of individual programs, but it could also be accomplished through research that surveys accredited OT programs across the country to gather data about specific assignments attached to those ACOTE standards that reference multiple settings, including the community. Based on data (either from individual program evaluation or comprehensive national research) programs could strengthen assessment measures to be sure standards that reference community settings are being comprehensively addressed.

5. Elicit ongoing feedback about student learning related to community-based practice. All programs have program evaluation mechanisms in place, and this can be an opportunity to find out whether students feel they have been adequately prepared for entry-level community-based practice. Data from FW evaluations may also meet this purpose.

6. Incorporate existing research that relates to community-based practice into instruction. All programs value evidence-based practice, but programs might do more to ensure that 
students are exposed to research that relates to community practice as well as research that relates to more traditional institution-based practice. Along with incorporating the research, interested faculty might consider pursuing lines of scholarship that actively add to the existing literature on community-based OT.

7. Teach students to value lifelong learning and to accept it as a professional and ethical responsibility. The study's findings clearly indicate that OTs in community-based practice employ self-directed learning strategies to develop expertise. Students should be encouraged to see their formal OT education as a foundation for practice, while also understanding that they will need to be active learners throughout the course of their careers. This is true in all areas of OT practice, but may be particularly valuable in advanced areas of practice or areas of practice (such as community-based) where access to OT collaboration and mentorship is limited.

8. Several of these recommendations may contribute to a greater acceptance of communitybased practice as an intermediate area of practice rather than an advanced area. Increasing students' exposure to community-based FW, instruction from community-based clinicians, and community-specific content, assignments, and research may all help students feel more confident about entering community-based roles earlier in their careers. Increasing recognition for community-based and emerging roles may also shift faculty attitudes; this is important because faculty advisors are often influential in guiding students' entry-level practice decisions. In addition, as more faculty members pursue lines of research related to community-based and emerging practice, there will be additional evidence-based resources available to both students and clinicians: scholarly 
publications, practice publications and resources, conference presentations, continuing education courses, blogs and online forums, for example.

\section{Recommendations for Employers and Continuing Education (CE) Providers}

1. Employers: Commit to facilitating both formal and informal opportunities for mentorship. Mentorship and guidance from experienced therapists was one of the primary suggestions of study respondents. Alternatives to consider include group mentorship, mentorship outside one's discipline, and online or "e-mentorship" (Jacobs, Doyle, \& Ryan, 2015; Sangole, Abreau, \& Stein, 2006)

2. Employers: Explore options for making continuing education more accessible to practitioners. These could include on-site training options that are based on feedback from employees, providing access to online resources such as journals and webinars, and possibly providing some reimbursement for professional development expenses such as professional dues, workshops, textbooks, and conference attendance.

3. Employers: Examine ways in which the work environment(s) either foster or inhibit collaboration. Look for ways to bring people together to share ideas and resources and to support one another in building practice expertise. This might include team meetings, online forums, and team building activities. Seek feedback about barriers as well, and support practitioners to implement innovative solutions.

4. CE providers: Evaluate CE options and their relevance to community-based practice. Consider the best ways to reach far-flung community-based OTs; these may be online webinars, on-demand trainings, and web-based resources rather than traditional workshops and conferences. Review existing research and seek stakeholder feedback to determine topics of most relevance. 


\section{Limitations}

This study had some significant limitations, and as expected most related to sampling. Although the sample size was sufficient for the descriptive and qualitative analyses that were performed, the overall response rate was low. Because the AOTA database provided only mailing addresses (rather than e-mail addresses), the survey invitation was issued by mail. It is unknown how many of those envelopes were received and opened, and that was a recognized limitation in the methodology even before data collection began. Because the response rate was low, the study's sample may not be representative of the target population from which it was drawn: AOTA members who were members of the Home and Community Health, Work and Industry, or Mental Health Special Interest Section. It should be noted that the target population may also not have been representative of community-based OTs as a whole, since not all OTs are members of AOTA. A second limitation was sample composition. Study respondents were mostly experienced OTs, with more than half having ten plus years of experience in communitybased practice, and the majority having $20+$ years of OT experience generally. There is no research to indicate whether this level of experience is typical of community-based OTs, but it is likely that therapists with significant experience will have different perceptions than those with less experience. Finally, the survey instrument posed a possible limitation, since it was not a validated tool. Although it was pilot tested, there is no guarantee that it accurately assessed the most effective professional development strategies. And while the survey was guided by an evidence-based conceptual framework, there is no way to be sure that respondents understood competency areas or professional development strategies in the way those terms were conceptualized by Scaffa (2014) and King (2009) or by the researcher. 


\section{Recommendations for Future Research}

This study was intended to be exploratory, since no other studies were found to have specifically addressed competence development in community-based OT. Not surprisingly, it raised as many questions as it answered. The following are just a few possibilities for further research:

- A qualitative exploration of competence development. While the descriptive statistics yielded by this study provide a starting point, it would be intriguing to find out more about why different strategies are considered more or less effective. This could be accomplished through interviews or focus groups in a more in-depth way than was possible with a survey.

- Further exploration of the differences that may exist between novice and expert clinicians. This study represented the views of a mostly very-experienced group of community-based OTs. It would be interesting to delve into the competence development process as it changes over time.

- Comparison of competency development in community-based practice with competency development in other advanced areas of OT practice. Are self-directed learning strategies equally prominent in other areas of practice? If so, that may have implications for our understanding of the development of clinical expertise generally.

- Analysis of existing continuing education options. Several previous studies have called for more tailored continuing education options, but there is no current evidence of what is actually being offered by CE providers in the United States.

- Analysis of community-based learning activities within OT curricula. All accredited OT programs must address standards that include community-based practice, but other than a 
few published descriptions of specific learning activities, there is no clear evidence of how this is being accomplished.

- Further research that may support the development of practice guidelines specific to community-based practice. AOTA currently develops practice guidelines for specific areas of practice, and these guidelines help to define OT domain, process, and evidencebased interventions (AOTA, n.d.). AOTA practice guidelines are reviewed and approved by the Agency for Healthcare Research and Quality (AHRQ), which maintains a clearinghouse of summaries of evidence-based clinical practice guidelines across a wide range of healthcare disciplines (AHRQ, n.d.). While current research is insufficient to serve as the basis for specific community-based OT practice guidelines, an accumulation of future research may provide a rationale for the development of such guidelines.

\section{Conclusion}

In summary, this study found self-directed learning to be the most effective strategy for developing the competencies needed for community-based practice. Professional development strategies such as continuing education, workplace trainings, and mentorship and feedback were chosen less frequently, and overall, formal OT education was the least-chosen strategy. Most study participants considered their formal OT education and available professional development options either average or effective, however they also had many suggestions for improvement. The most common suggestions included increasing community-based fieldwork, increasing the role of community-based practitioners in the education process through guest lecturing and adjunct teaching, increasing mentorship options, and providing more education specific to the knowledge needed to practice and advance in diverse community-based settings. 
The study's findings have a number of possible interpretations. Respondents' selection of self-directed learning as a primary strategy for developing competencies may reflect the learning preference of expert clinicians, or may simply be a quirk of the sample. It may be seen to validate the importance of lifelong learning and self-directed learning, particularly for practitioners in advanced or specialized areas of practice. It is also possible that many respondents chose this option because they did not feel that formal OT education or existing professional development options fully meet their needs. In that case, there may be more that OT programs, employers, and continuing education providers can do to ensure that resources are available to support the preparation and development of community-based OTs. This study suggests that drawing on the expertise of community-based OTs through FW education, curriculum, and mentorship; increasing specific educational content; increasing evidence-based resources; and increasing recognition for diverse OT roles may all contribute to enhanced competence development. Further research and resources are needed to support those OTs who work in clients' homes, workplaces, and a wide variety of other community-based settings. 


\section{References}

Accreditation Council for Occupational Therapy Education (2011). Accreditation standards for a Masters-degree-level educational program for the occupational therapist. Retrieved from http://www.aota.org/Education-Careers/Accreditation/StandardsReview.aspx

Adam, K., Peters, S., \& Chipchase, L. (2013). Knowledge, skills, and professional behaviors required by occupational therapist and physiotherapist beginning practitioners in workrelated practice: A systematic review. Australian Journal of Occupational Therapy, 60, 76-84. http://dx.doi.org/10.1111/1440-1630.12006

Adam, K., Strong, J., \& Chipchase, L. (2014). Readiness for work injury management and prevention: Important attributes for early graduate occupational therapists and physiotherapists. Work, 48, 567-578. doi: 10.3233/WOR-141912

Alsop, A. (2013). Continuing professional development in health and social care: Strategies for lifelong learning ( $2^{\text {nd }}$ ed.). Chichester, West Sussix: John Wiley \& Sons Ltd.

American Occupational Therapy Association (n.d.). About occupational therapy. Retrieved from http://www.aota.org/About-Occupational-Therapy.aspx

American Occupational Therapy Association (n.d.). Practice guidelines. Retrieved from http://www.aota.org/Practice/Researchers/practice-guidelines.aspx

American Occupational Therapy Association (2010a). Scope of practice. American Journal of Occupational Therapy, 64(6, supplement), S70-S77.

American Occupational Therapy Association (2010b). Standards for continuing competence. American Journal of Occupational Therapy, 64(6, supplement), S103-S105. 
American Occupational Therapy Association (2014). Research agenda: Occupational therapy education research agenda. American Journal of Occupational Therapy, 68, S83-S86. doi: 10.5014/ajot.2014.685S06

American Occupational Therapy Association (2015a). New community behavioral health centers: Occupational therapy listed in final criteria. Retrieved from http://www.aota.org/Advocacy-Policy/Congressional-Affairs/Legislative-Issues Update/2015/community-behavioral-health-occupational-therapy-criteria.aspx American Occupational Therapy Association (2015b). 2015 salary and workforce survey: Executive summary. Retrieved from https://www.aota.org/Education-Careers/Advance Career/Salary-Workforce-Survey.aspx

American Occupational Therapy Association. (2015c). Occupational therapy code of ethics (2015). American Journal of Occupational Therapy, 69(Suppl. 3), 6913410030. http://dx.doi.org/10.5014/ajot.2015.696S03

American Occupational Therapy Association (2106). Issues in licensure. Retrieved from http://www.aota.org/Advocacy-Policy/State-Policy/Licensure.aspx

American Speech-Language-Hearing Association (2008). Report on emerging areas of clinical practice. Retrieved from http://www.asha.org/academic/reports/EmergingAreasClinicalPractice/

Baum, L. C. (2006). Harnessing opportunities and taking responsibility for our future. American Journal of Occupational Therapy, 60(3), 249-257. http://dx.doi.org/10.5014/ajot.60.3.249

Benner, P. (1984). From novice to expert: Excellence and power in clinical nursing practice. Menlo Park, NJ: Addison-Wesley 
Bowman, P. (2014). Ergonomics and prevention of work-related injuries. In M. E. Scaffa, M. \& S. M. Reitz (Eds.), Occupational therapy in community-based practice settings $\left(2^{\text {nd }}\right.$ ed., pp. 223-242). Philadelphia, PA: F. A. Davis Company.

Braveman, B. (2016). Assessing and promoting clinical and managerial competency. In B. Braveman (Ed.), Leading and managing occupational therapy services: An evidencebased approach (2 ${ }^{\text {nd }}$ ed., pp. 297-326). Philadelphia, PA: F. A. Davis Company.

Braveman, B., \& Suarez-Balcazar (2009). Social justice and resource utilization in a communitybased organization: A case illustration of the role of the occupational therapist. American Journal of Occupational Therapy, 63(1), 13-23. http://dx.doi.org/10.5014/ajot.63.1.13

Brown, D. (2014). Health policy perspectives - habilitative services: An essential health benefit and an opportunity for occupational therapy practitioners and consumers. American Journal of Occupational Therapy, 68, 130-138.

http://dx.doi.org/10.5014/ajot.2014.682001

Carrier, A., Levasseur, M., Bedard, D., \& Desrosiers, J. (2010). Community occupational therapists' clinical reasoning: Identifying tacit knowledge. Australian Journal of Occupational Therapy, 75, 356-365. http://dx.doi.org/10.1111/j.1440-1630.2010.00875.x

Creswell, J. W. (2013). Qualitative inquiry and research design: Choosing among five approaches ( $3^{\text {rd }}$ ed.). Thousand Oaks, CA: SAGE.

Dillman, D. A., Smythe, J. D, \& Melani Christian, L. (2014) Internet, phone, mail, and mixedmode surveys: The tailored design method ( $4^{\text {th }}$ ed.). Hoboken, NJ: John Wiley and Sons, Inc. 
Dillon, M. B., Dillon, T. H., King, R. M., \& Chamberlin, J. L. (2007). Interfacing with community mental health services: Opportunities for occupational therapy and level II fieldwork education. Occupational Therapy in Health Care, 21, 91-104. doi:10.1300/J003v21n01_07

Fazio, L. A. (2008). Developing occupation-centered programs for the community ( $2^{\text {nd }}$ ed.). Upper Saddle River, NJ: Pearson Education Inc.

Fisher, G., \& Friesema, J. (2013). Health policy perspectives: Implications of the Affordable Care Act for occupational therapy practitioners providing services to Medicare recipients. American Journal of Occupational Therapy, 67, 502-506. http://dx.doi.org/10.5014/ajot.2013.675002

Fox, V. (2013). Professional roles in community mental health practice: Generalist vs specialist. Occupational Therapy in Mental Health, 29, 3-9. http://dx.doi.org/10.1080/0164212X.2013.760276

Gat, S., \& Ratzon, N, V. (2014). Comparison of occupational therapy students' perceived skills after traditional and nontraditional fieldwork. American Journal of Occupational Therapy, 68, e47-e54. http://dx.doi.org/10.5014/ajot.2014.007732

Gillette, N. P. (1998). Dedication: A vision for our future. American Journal of Occupational Therapy, 52(5), 318-319. http://dx.doi.org/10.5014/ajot.52.5.318

Hanft, B. E., \& Anzalone, M. (2001). Issues in professional development: Preparing and supporting occupational therapists in early childhood. Infants and Young Children, 13(4), 67-78. http://dx.doi.org/10.1097/00001163-200113040-00013 
Holmes, W. M., \& Scaffa, M. E. (2009a). An exploratory study of competencies for emerging practice in occupational therapy. Journal of Allied Health, (38)2, 81-90. Retrieved from CINAHL (19623789).

Holmes, W., \& Scaffa, M. (2009b). The nature of emerging practice in occupational therapy: A pilot study. Occupational Therapy in Health Care, 23(3), 189-206. http://dx.doi.org/10.1080/07380570902976759

Institute of Medicine (2009). Redesigning continuing education in the health professions: Report brief. Retrieved from http://nationalacademies.org/hmd/ /media/Files/Report\%20Files/2009/RedesigningContinuing-Education-in-the-Health-Professions/RedesigningCEreportbrief.pdf

Jacobs, K., Doyle, N., \& Ryan, C. (2015). The nature, perception, and impact of e-mentoring on post-professional occupational therapy doctoral students. Occupational Therapy in Health Care, 29(2), 201-213. http://dx.doi.org/10.3109/07380577.2015.1006752

Kendall, E., Muenchberger, H., \& Catalano, T. (2009). The move toward community-based rehabilitation in industrialized countries: Are we equipped for the challenge? Disability and Rehabilitation, 31(26), 2164-2173. http://dx.doi.org/10.3109/09638280902939734

King, G. (2009). A framework of personal and environmental learning-based strategies to foster therapist experience. Learning in Health and Social Care, 8(3), 185-199. http://dx.doi.org/10.1111/j.1473-6861.2008.00210.x

Lamb, A. J., \& Metzler, C. A. (2014). Health policy perspectives-defining the value of occupational therapy: A health policy lens on research and practice. American Journal of Occupational Therapy, 68, 9-14. http://dx.doi.org/10.5014/ajot.2014.681001 
Lysack, C., Stadnyk, R., Paterson, M., McLeod, K., \& Krefting, L. (1995). Professional expertise of occupational therapists in community practice: Results of an Ontario survey. Canadian Journal of Occupational Therapy, 62, 138-147.

http://dx.doi.org/10.1177/000841749506200305

McColl, M. (1998). What do we need to know to practice occupational therapy in the community? American Journal of Occupational Therapy, 52, 11-18. http://dx.doi.org/10.5014/ajot.52.1.11

Merriam, S. B. (2009). Qualitative research: A guide to design and implementation. San Francisco, CA: John Wiley \& Sons, Inc.

Metzler, C. (2015). Jimmo: The court case that promotes skilled therapy. Retrieved from http://www.aota.org/advocacy-policy/federal-reg-affairs/news/2015/jimmo-court-casepromotes-skilled-therapy.aspx

Meyers, S. K. (2010). Community practice in occupational therapy: A guide to serving the community. Sudbury, MA: Jones and Bartlett Publishers Inc.

Mitchell, R., \& Unsworth, C. A. (2004). Role perceptions and clinical reasoning of community health occupational therapists undertaking home visits. Australian Journal of Occupational Therapy, 51, 13-24. http://dx.doi.org/10.1111/j.1440-1630.2004.00372.x

Moon, J. A. (2004). Reflection in learning and professional development: Theory and practice. New York, NY: Routledge Falmer.

Murdoch-Eaton, S., \& Whittle, D. (2012). Generic skills in medical education: Developing the tools for successful lifelong learning. Medical Education, 46, 120-128. http://dx.doi.org/10.1111/j.1365-2923.2011.04065.x 
National Board for Certification in Occupational Therapy (2016). Certificants. Retrieved from http://www.nbcot.org/certificants

New York State Assembly (n.d.). A07488 summary. Retrieved from http://nyassembly.gov/leg/?bn=A07488\&term=2015

Parry, S. B. (1998). Just what is a competency? And why should you care? Training, 35(6), 5864. Retrieved from ERIC (EJ566039).

Portney, L. G., \& Watkins, M. P. (2015). Foundations of clinical research: Applications to practice ( $3^{\text {rd }}$ ed.). Philadelphia, PA: F. A. Davis.

Professional development. (n.d.). In Macmillan dictionary. Retrieved from http://www.macmillandictionary.com/us/dictionary/american/professional-development

Ramsey, R. (2011). Voices of community-practicing occupational therapists: An exploratory study. Occupational Therapy in Health Care, 25(2-3), 140-149. http://dx.doi.org/10.3109/07380577.2011.569856

Riegel, S. K., \& Eglseder, K. (2009). Occupational justice as a quality indicator for occupational therapy services. Occupational Therapy in Health Care, 23(4), 288-301. http://dx.doi.org/10.3109/07380570903236500

Sakellarious, D., \& Pollard, N. (2006). Rehabilitation: In the community or with the community? British Journal of Occupational Therapy, 69(12), 562-566. http://dx.doi.org/10.1177/030802260606901205

Sangole, A. P., Abreau, B. C., \& Stein, F. (2006). Mentoring review and reflections. Occupational Therapy in Health Care, 20(1), 1-16. http://dx.doi.org/10.1080/J003v20n01_01 
Scaffa, M. E. (2014). Community-based practice: Occupation in context. In M. E. Scaffa, \& S. M. Reitz (Eds.), Occupational therapy in community-based practice settings $\left(2^{\text {nd }}\right.$ ed., pp. 1-18). Philadelphia, PA: F. A. Davis Company.

Scaffa, M. E., Guillory Caraway, E., \& Takehara, S. (2014). Future directions in communitybased practice. In M. E. Scaffa \& S. M. Reitz (Eds.), Occupational therapy in community-based practice settings ( $2^{\text {nd }}$ ed., pp. 421-439). Philadelphia, PA: F. A. Davis Company.

Schaber, P. (2010). Teaching program development and evaluation through a service learning project in community-based adult day services. Occupational Therapy in Health Care, 24(1), 107-117. http:// doi: 10.3109/07380570903329644

Schon, D. A. (1983). The reflective practitioner: How professionals think in action. Basic Books.

Schostak, J., Davis, M., Hanson, J., Schostak, J., Brown, T., Driscoll, P....Jenkins, N. (2010). Effectiveness of continuing professional development project: A summary of findings. Medical Teacher, 32, 586-592. http://dx.doi.org/10.3109/0142159X.2010.489129

Stovholt, T. M., \& Starkey, M. T. (2010). The three legs of the practitioner's learning stool: Practice, research/theory, and personal life. Journal of Contemporary Psychotherapy, 40, 125-130. http://dx.doi.org/10.1007/s10879-010-9137-1

United States Department of Health and Human Services (n.d.). Essential health benefits. Retrieved from http://www.hhs.gov/opa/affordable-care-act/health-services-andbenefits/essential-health-benefits/index.html\#

University of New England (2010). Policies, procedures, and guidance on research with human subjects. Retrieved from http://www.une.edu/sites/default/files/UNE-IRB-P-P-2010-804.pdf. 
Webster-Wright, A. (2009). Reframing professional development through understanding authentic professional learning. Review of Educational Research, 79(2), 702-739. http://dx.doi.org/10.3102/0034654308330970

Wood, R., Fortune, T., \& McKinstry, C. (2013). Perspectives of occupational therapists working in primary health promotion. Australian Journal of Occupational Therapy, 60, 161-170. doi: $10.1111 / 1440-1630.12031$

World Health Organization (2016). Community-based rehabilitation. Retrieved from http://www.who.int/disabilities/cbr/en/

Wray, E. L., \& Mortenson, P. A. (2011). Cultural competency in occupational therapists working in early intervention therapy programs. Canadian Journal of Occupational Therapy, 78(3), 180-186. http://dx.doi.org/10.2182/cjot.2011.78.3.6

Yamkovenko, S. (n.d.) The emerging niche: What's next in your area of practice? Retrieved from http://www.aota.org/practice/manage/niche.aspx 
Appendix A

AOTA RENTAL LIST APPLICATION FORM

\section{AOTA List Rental Service}

\section{$\underline{\Lambda O T \Lambda} \underline{\underline{n}}$}

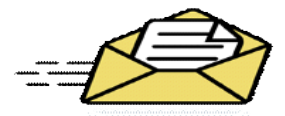

\section{MAILING LIST POLICIES \& PRICES FOR STUDENT RESEARCHERS}

Requirements:

- You must currently be enrolled in an accredited occupational therapy program.

- You may only use the list for a project needed for graduation from an accredited OT program.

- To process an order we need a completed order form, sample of the mailing piece and signed List Rental Agreement. (Please include all mailing pieces to be sent to our members. (i.e., cover letter, survey, follow-up postcards))

- The mailing pieces or on-line survey cannot reference AOTA in any way.

- The names and addresses shall not be copied, reused, sold, electronically reproduced, or used by any party except as specified in the written order and sample mailing piece submitted with the order. No second use, telemarketing, tagging, appending, or list enhancement of any kind is permitted from a list without permission of AOTA.

- All lists must be destroyed after completion of your mailing.

You may choose one of the following options:

1) Excel file sent via e-mail (one-time use; maximum 500 names) $\$ 70.00$

(Each additional use is subject to an additional charge of \$35.00)

2) Excel file sent via e-mail (maximum 250 names) for two-time use

$\$ 70.00$

Random sample: No extra charge

**All electronically sent mailing lists are 'seeded' with a minimum of one decoy name and address to monitor list use. Your list will contain an extra name(s), so your sample group will be the size you require. For example, if you request 500 names, 1 or more additional name(s) may be on the list for list monitoring. 
Questions? Email listrental@aota.org

Call Claire Foster, List Rental Manager at 800-877-1383, Ext. 2749 or fax: (240) 762-5156

AOTA does not provide email addresses

\section{AOTA List Rental Service}

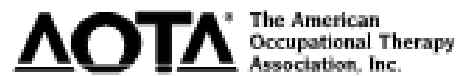

\section{AOTA List Rental Service Order Form for Students}

Please check appropriate boxes for each selection you wish to include in your mailing list.

Email addresses are not available.

Product Format (List is sent as an attachment to an email):

ASCII Comma De-limited

Excel

Member Category (Check which member categories you want to include on the list.)

Occupational Therapist (OT)

Occupational Therapy Assistant (OTA)

\section{Geographical Area}

US and International

US Only (includes Puerto Rico)

States(s) (Specify):

Special Interest Sections (SIS) (Members can have up to three SISs) Please check all that you want to include:
Developmental
Home/Community
Therapy Education)
Disabilities Health
Mental Health
Sensory Integration
Technology
Gerontology
Early Intervention \&
Work and Industry School Systems
Physical Disabilities
Education
Administration and (Occupational Management

Members can have up to three SISs. One is considered primary and the other two secondary. Please check if you want primary only or primary and secondary. 


\section{Primary SIS Only}

Primary and Secondary SIS

* SISs are updated with each membership join or renewal, but work setting information is optional and may not get updated each time. If interested in any work settings, please combine with one or more SISs that are compatible, thus ensuring the work setting is still relevant to their current SISs. For example, if you check Rehabilitation Hospital/Center, you may want to also check the Physical Disabilities SIS.

Work Settings Please check all that you want to include:

Academic

Early Intervention

Free Standing

Outpatient

Home Health

Hospital (Non-

Mental

Health)

Neonatal Unit of

Hospital
Private Practice

School System

$\square$ Rehabilitation

Hospital/Cent

er

Sub-acute

Facility/Unit

Mental Health

Setting
Work/Industry/Ergon omics

Community based (e.g. Easter Seal, homeless shelter)

Skilled Nursing/Long Term Care

\section{List Sequence}

Numeric ZIP

Alphabetical

Random Selection (Specify total number desired):

Add'1 Uses(Specify number of uses): 


\section{AOTA List Rental Service}

\section{AOTA List Rental Service Order Form for Students}

\section{Bill To}

Name:

Institution/Company:

Street:

City:

State/ZIP:

\section{Ship To}

Name:

Email address for mailing list delivery:

Purchaser's Phone

Purchasher's Fax

Contact Person

Contact Email

OT School Currently Attending:

AOTA Membership Number (if applicable)

Orders will not be processed without a draft or final copy of the mailing piece. 
Mail or Fax order form and a sample of the mailing piece to:

American Occupational Therapy Association

List Rental Service

4720 Montgomery Lane, Suite \#200

Bethesda, MD 20814-3449

Phone 800-877-1383, Ext. 2749 Fax 240-762-5156

E-mail: listrental@aota.org

All orders are final

AOTA does not provide email addresses 
Appendix B

\section{SURVEY COVER LETTER/ INVITATION TO PARTICIPATE}

Dear Colleague:

Have you ever wondered what makes community-based occupational therapists unique? You are invited to participate in a research study designed to explore how OTs develop the unique skills and competencies needed in community-based practice.

If you have worked in any community-based setting (home health, EI, community mental health, vocational, emerging areas etc) within the past 3 years, I would sincerely appreciate your participation in this study. There are two easy options for participating:

1. Use the survey link. Just type "xxxx.question.pro" into your browser's address box and you will be taken directly to the questionnaire. You can share this link with other community-based OTs who might be interested, but please take the survey only once!

2. Scan the QR code at the bottom of the page with your phone. This requires a free app. Scanning will also take you directly to the questionnaire.

This invitation will only be mailed once, so please consider completing the questionnaire now! The survey only takes about 5 minutes and I think you may find it interesting. This study has been approved by the Institutional Review Boards (IRB) of the University of New England and Keuka College. Participating in this study is voluntary. Completing the questionnaire implies your consent to have your data included in the study. All responses will be anonymous and data will be analyzed in 
aggregate. Please provide your e-mail at the end of the survey if you would like a copy of the final abstract/ results.

Thank you so much for participating in this study and for helping a colleague with her dissertation research. Please feel free to contact me or my adviser (Dr. Carey Clark cclark14@une.edu ) with any questions.

Thanks and happy New Year!

Sunny Winstead, MS, OTR/L

Assistant Professor of Occupational Therapy, Keuka College

swinstead@keuka.edu

$607-546-5244$

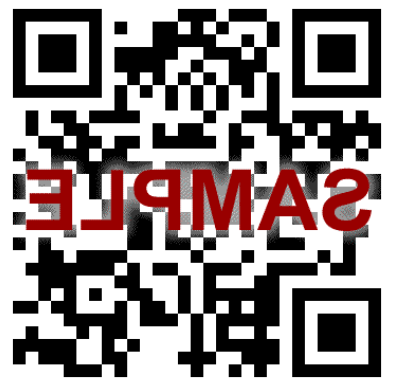


Appendix C

\section{SURVEY CONTENT}

\section{Competence Development in Community-Based Occupational Therapy}

\section{Research Survey}

1. Do you currently work approximately 15 hours/week or more in a community-based practice setting (see examples in \#6 below)?
$\square$ Yes
$\square$ No

2. If not working in a community-based setting now, have you worked approximately 15 hours/week or more in a community-based setting within the past 3 years?

$\square$ Yes $\quad \square$ No (this response will terminate the electronic survey)

3. Please describe your professional status.

Occupational therapist, currently in clinical OT practice at least part time

Occupational therapist, not currently in clinical OT practice at least part time

4. Please identify your gender.

$\square$ Female

$\square$ Male 
5. What is your highest level of OT education?

$\square$ bachelor's $\square$ master's $\quad \square$ entry-level doctorate $\quad \square$ post-professional doctorate

6. Please check the area(s) in which you have community-based practice experience.

Home health

Vocational services

Community mental health

Group homes

$\square$ Hospice $\square$ Early intervention (EI)

$\square$ Ergonomics

$\square$ Wellness and health promotion

$\square$ Public health

$\square$ Other:

7. About how many years have you been an OT?
$\square 0-1$ year
$\square 11-15$ years
$2-5$ years
$\square 16-20$ years
6-10 years
more than 20 years

8. About how many years (total) have you worked in community-based OT?
$\square 0-1$ year
$\square 11-15$ years
2-5 years
$\square 16-20$ years
6-10 years
$\square$ more than 20 years 
According to the literature, OTs in community-based practice need a number of unique competencies or skills. Each question below focuses on one unique competency (in bold) and asks how you have developed this competency.

Note: You can click the question mark for a brief definition of the competency. Definitions are adapted from Scaffa, M. E. (2014). Community-based practice: Occupation in context. In Scaffa, M. E. \& Reitz, S. M. (Eds.), Occupational therapy in community-based practice settings (2 ${ }^{\text {nd }}$ ed., pp. 1-18). Philadelphia, PA: F. A. Davis Company.

9. Which type of professional development have you found most effective in developing the performance skills that you need for community-based practice (choose only one)?

$\square$ Formal OT education (OT school)

Self-directed learning (on-the-job experience)

$\square$ Feedback and mentoring

Workplace trainings, inservices, and teamwork

Continuing education (conferences, workshops, online education)

$\square$ Other:

10. Which type of professional development have you found most effective in developing the specific knowledge that you need for community-based practice (choose only one)?

$\square$ Formal OT education (OT school)

Self-directed learning (on-the-job experience)

Feedback and mentoring 
Workplace trainings, inservices, and teamwork

Continuing education (conferences, workshops, online education)

Other:

11. Which type of professional development have you found most effective in developing the critical reasoning skills that you need for community-based practice (choose only one)?

Formal OT education (OT school)

Self-directed learning (on-the-job experience)

$\square$ Feedback and mentoring

Workplace trainings, inservices, and teamwork

Continuing education (conferences, workshops, online education)

Other:

12. Which type of professional development have you found most effective in developing the ethical reasoning skills that you need for community-based practice (choose only one)?

$\square$ Formal OT education (OT school)

Self-directed learning (on-the-job experience)

Feedback and mentoring

Workplace trainings, inservices, and teamwork

Continuing education (conferences, workshops, online education)

$\square$ Other: 
13. Which type of professional development have you found most effective in developing the interpersonal communication skills that you need for community-based practice (choose only one)?

$\square$ Formal OT education (OT school)

Self-directed learning (on-the-job experience)

Feedback and mentoring

Workplace trainings, inservices, and teamwork

Continuing education (conferences, workshops, online education)

Other:

14. Which type of professional development have you found most effective in developing the personal qualities and characteristics (such as flexibility, independence, creativity...) that you need for community-based practice (choose only one)?

$\square$ Formal OT education (OT school)

$\square$ Self-directed learning (on-the-job experience)

$\square$ Feedback and mentoring

Workplace trainings, inservices, and teamwork

$\square$ Continuing education (conferences, workshops, online education)

Other: 
15. How effective was your OT education in preparing you for community-based OT practice?

$\square$ Very effective $\square$ Effective $\quad \square$ Average $\quad \square$ Ineffective $\quad \square$ Very ineffective

16. How effective are existing professional development resources (continuing education courses, online education, journals and research resources etc) for improving your skills for communitybased OT practice?

$\square$ Very effective $\square$ Effective $\quad \square$ Average $\quad \square$ Ineffective $\quad \square$ Very ineffective

17. What are your suggestions for improving academic training and continuing education for OTs in community-based practice?

Thank you so much for completing this survey! Feel free to share this link with other community practice OTs who might be interested, but each person should take the survey only once. If you would like a copy of the final abstract, please provide your e-mail here: 


\section{Appendix D}

\section{IRB APPROVAL FROM THE UNIVERSITY OF NEW ENGLAND}

Institutional Review Board

Olgun Guvench, Chair

Biddeford Campus

11 Hills Beach Road

Biddeford, ME 04005 (207)602-

$2244 \mathrm{~T}(207) 602-5905 \mathrm{~F}$

Portland Campus

716 Stevens Avenue

Portland, ME 04103

To:

Cc:

From:

Date:

Project \# \& Title:
Sunny Winstead

Carey Clark

Olgun Guvench

November 18, 2016

111816-011, Competency Development in Community-Based Occupational Therapy (Initial)

The Institutional Review Board (IRB) for the Protection of Human Subjects has reviewed the above captioned project, and has determined that the proposed work is exempt from IRB review and oversight as defined by 45 CFR $46.101(b)(2)$.

Additional IRB review and approval is not required for this protocol as submitted. If you wish to change your protocol at any time, you must first submit the changes for review.

Please contact Olgun Guvench at (207) 221-4171 or oguvench@une.edu with any questions. Sincerely,

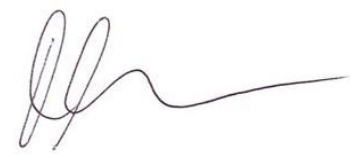

Olgun Guvench, M.D., Ph.D. IRB Chair

IRB\#: 111816-011

Submission Date: 11/14/16

Status: Exempt, 45 CFR 46.101(b)(2)

Status Date: $11 / 18 / 16$ 
Appendix E

\section{WRITE-IN RESPONSES PROVIDED IN THE CATEGORY “OTHER”}

1. Most Effective Strategy for Developing Performance Skills

Experience.

2. Most Effective Strategy for Developing Specific Knowledge

Prior work experience in various settings.

3. Most Effective Strategy for Developing Critical Reasoning Skills

None.

4. Most Effective Strategy for Developing Ethical Reasoning Skills

Special interest section information/ AOTA resources.

5. Most Effective Strategy for Developing Interpersonal Communication Skills

Master's degree in Health Service Management.

6. Most Effective Strategy for Developing Personal Qualities and Characteristics

My personal occupational history.

Church study and growth.

Master's degree in Health Service Management.

I think some people have more natural ability in these skill areas. I do not think these are typically "developed" via training. I believe that personal characteristics may influence OT choices in pursuing innovative community practice

Experience.

Army veteran. 